\title{
The Impact of Pension Funding Mechanisms on the Stability and Payoff from Swiss DC Pension Schemes: A Sensitivity Analysis*
}

\author{
Philipp Müller, Joël Wagner ${ }^{\dagger}$
}

\begin{abstract}
Adequately funding occupational pension funds is a major concern for society in general and individual contributors in particular. The low returns accompanied with high volatility in capital markets have put many funds in distress. While the basic contributions are mostly defined by the state, the fund's situation may require additional contributions from the insureds or may allow the distribution of surpluses. In this paper, we focus on the accumulation phase of a defined contribution plan in Switzerland with minimum returns and annual solvency targets in terms of an assets-to-liabilities funding ratio. From the viewpoint of the pension fund, we evaluate the outcome of selected funding mechanisms on the solvency situation. Taking the perspective of the contributors, we analyze the payoff and the utility. Combining both prospects, we discuss the boundary values that trigger the various participation mechanisms and their impact. We find that remediation measures, while stabilizing the fund, yield a higher volatility in the insureds contributions. Further, surplus distributions lower the relative payoff utility of the funds members and increase the frequency of remediation measures. Overall, insureds and pension funds will profit from a cautious surplus distribution policy that focuses on keeping the stability high and lowers the volatility of the result.
\end{abstract}

\section{Introduction}

Since the introduction of the Swiss pension system and occupational pension funds (2nd pillar) in particular, the demographic and capital market framework conditions have changed. Life expectancy is increasing, while birthrate is decreasing, causing the ratio of the number of active workers to the number of retirees to decline over the years (see OECD, 2015b). In the financial markets, many asset classes have delivered historically low returns and at the same time exhibited increased volatility in the last two decades (see OECD, 2015a).

The demographic issues and changing capital markets from the last financial crisis and ongoing turbulences are highlighted by most practitioners (see Credit Suisse, 2014). There are also other factors that change the environment. For example, at the society level, family and living structures along with work conditions have changed (see, e.g., Maas et al., 2015). Flexibility

\footnotetext{
${ }^{*}$ This is a post-peer-review, pre-copyedit version of an article published in The Geneva Papers on Risk and Insurance - Issues and Practice. The final authenticated version is available online at: https://doi.org/10.1057/s41288-017-0048-1.

${ }^{\dagger}$ Philipp Müller (philipp.muller.1@unil.ch) and Joël Wagner (joel.wagner@unil.ch) are with the Department of Actuarial Science, University of Lausanne, Faculty HEC, Extranef, 1015 Lausanne, Switzerland. Both authors acknowledge financial support from the Swiss National Science Foundation (grant no. 100018_159428). The authors are thankful for the comments on earlier versions of this manuscript by participants of the Western Risk and Insurance Annual Meeting 2016, the International Conference Mathematical and Statistical Methods for Actuarial Sciences and Finance 2016, and the Lyon-Lausanne Seminar 2016.
} 
in work time management, statutory and effective retirement age and new disability and oldage dependency challenges need to be considered. Many technical parameters in Swiss pension funds (e.g., the minimum interest rate, the conversion rate) and their adaptations depend on political decisions. Reforms have been strongly rejected in the last few years, and the definitions of technical and actuarial parameters have undergone lengthy political processes. The currently planned reform in Switzerland called "Altersvorsorge 2020"1 only yields partial answers. In the 2008 financial crisis and its aftermath, the solvency of many pension funds has been stressed. The funding ratio has dropped below $100 \%$ in many cases, which has put pressure on funds to move towards consolidation and sustainability considerations (see Swisscanto, 2015). This pressure comes along with operational risks with regard to compliance, higher transparency and governance requirements. Furthermore, one has to consider increasing wealth transfers between younger and older contributor groups (Avanzi and Purcal, 2014; Eling, 2012) or potentially unfair mechanisms regarding employees who change their employer and pension fund. ${ }^{2}$ These changes pose challenges to the Swiss system and the ones in other countries. Many aspects of these problems have been discussed by practitioners and politicians, but they have been given much less attention in academic research. For example, pension funds in good shape have started paying bonuses to their policyholders while it is unclear whether this is optimal and increases their utility (see, e.g. Jacquemart, 2014; Lisse, 2014). Independent research and a solid academic foundation are important in an area where the stakeholders, contributors, pension funds, actors from the industry and politicians have diverging interests and opinions. This is why we focus on the following research question: What is the impact of funding mechanisms on the pension fund stability and the utility of the insured?

While our research holds true for the accumulation of funds in pension funds in many countries (with certain adaptations), we apply our modeling to the Swiss 2nd pillar pension system and study different dimensions of risk that affect pension schemes and their members. We study the impact that remediation measures and surplus distribution have on the stability and the payoff of a fund and the utility of its members. For this, we put the available funds at the term of the savings phase in relation to the total payments, i.e. regular contributions and remediation costs. Our research involves, among others, the adequate choice of parameters, the model's sensitivity and the impact of capital market scenarios. While this is adequate when analyzing the pension fund for the active insureds during the accumulation phase, limitations for drawing conclusions on the overall state of the fund exist (e.g., exclusion of the bonuses legally due to pensioners, credits and debits from mortality).

The academic literature analyzing different types of pension schemes is abundant. Sharpe (1976) is one of the first to rigorously analyze pension insurance provided by a sponsor. Black (1976) discusses both the optimal pattern of contributions and the optimal investment policy for the assets of a pension fund. Typically, stochastic pension fund modeling is used, as can be found in, e.g., O'Brien (1986), Bacinello (1988) and Dufresne (1989). The topic of asset allocation is studied from different perspectives in the literature as well. By using a simple stochastic model, Cairns et al. (2006) incorporate asset, salary and interest rate risk in the derivation of optimal investment strategies. While many actuarial papers analyze risk from demographic

\footnotetext{
${ }^{1}$ See http://www.bsv.admin.ch/altersvorsorge_2020, September 2016.

${ }^{2}$ Contributors changing their employer must change to the pension linked to the new company. Thereby, the assets are transferred whereas, e.g. potential remediation measures to improve the overall state of the pension fund, remain with the previous institution. Exceptions may apply, though, in the case of partial liquidation of the fund (see BVG, Art. 53).
} 
changes, financial risk in pension funds is less extensively considered in the existing literature: Most recently, by integrating assets and liabilities as well as solvency requirements, Berdin and Gründl (2015) consider a representative German life insurer and its asset allocation and outstanding liabilities. Generating a stochastic term structure of interest rates and stock market returns, the authors simulate investment returns in a multi-period setting. Based on empirically calibrated parameters, the evolution of the balance sheet is observed with a special focus on the solvency situation. Looking at participating life insurance contracts, Schmeiser and Wagner (2014) try to find a suitable value for the guaranteed interest rate. Their results show that as the risk-free interest rate approaches the guaranteed one, the equity falls to zero, as there is no longer any benefit from risky investments. This is relevant for pension funds too, as a minimum interest rate must be credited annually to the accounts of the contributors (see Broeders et al., 2011; Mirza and Wagner, 2016). A study of the impact of product features and contributor types on lapse in life insurance contracts can be found in Eling and Kiesenbauer (2013). Using a data set from a German life insurer, they conclude that the contract age and the premium type have the most important impact on the lapse rate. An analysis of the relationship between the liability structure and the asset allocation of defined benefit pension funds is performed by Alestalo and Puttonen (2006). Examining data from Finnish pension funds, the authors find that the liability structure does indeed influence the asset allocation, with the age structure of the members being one source of correlation. Examining data from different countries, Ghilarducci (2010) finds that there is a positive correlation between the spending for pensions and education. By combining a stochastic pension fund model with a traffic light approach, Braun et al. (2011) measure the shortfall probability of Swiss occupational pension funds in order to assist stakeholders in making decisions. Examining Dutch pension funds, Broeders et al. (2016) find empirical evidence for herding behavior in the asset allocation of institutions. By analyzing the optimality of supervisory rules, Chen and Clever (2015) show that both the security mechanisms and risk measures used by regulators influence the optimality of the regulations. The optimality of the boundaries used for the objective funding ratio and the optimal dividends are also discussed by Gerber and Shiu (2003). Finally, in a recent working paper, and closest to our undertaking, Avanzi et al. (2016) formally analyze the iteration of surplus dividend payments and the funding ratio of pension funds.

Recent statistical and industrial publications in Switzerland consider the current state of pension funds from a practical point of view. Often, they focus on the ongoing reforms, underline challenges that the system is facing, and discuss relevant funding ratios or intergenerational wealth transfers. An overview of the situation can be found in Albrecher et al. (2016). Some authors analyze the financial situation of funds, discuss possible reforms and ways to go forward (Bischofberger and Walser, 2011). Eling (2012) considers the current wealth distribution and transfer mechanisms among young and old generations in Switzerland. The aging population and the long-term (financial) perspectives are also in the focus of UBS (2014). In his recent book, Cosandey (2014) discusses reforms for fair intergenerational mechanisms and justice.

Our research aims at building on and extending the current state of knowledge by considering the framework of private Swiss pension funds, accounting for the currently changing environmental conditions, and including both the asset and liability perspectives. Using stochastic simulations and considering an individual contributor's account, we construct a model to assess the extra contribution and the surplus distribution mechanisms of defined contribution pension plans. From the institutional perspective, the funding ratio and the stability of the fund are taken into consideration. In particular, we look at the changes in the funding ratio over time for 
different funding mechanisms. This includes limits for the distribution of bonuses and methods for determining the additional contributions. We analyze what leads to greater stability of the fund and to higher final contributor utility. We study several scenarios for the capital market returns in order to examine the fund's ability to cope with periods of low and high market returns. We obtain the distribution of the final payoff and its sensitivity to the different mechanisms.

Our results indicate that the distribution of bonuses is connected to a higher volatility of the account value at retirement. For risk averse individuals, this leads to a decrease of their relative certainty equivalent. Thus, from a policyholder perspective, it is typically favorable not to get surpluses credited to the account during the contract period. With respect to pension fund policies, we believe that funds should consider measures that help reducing the volatility in the outcomes (e.g. by distributing less, less often, or accumulating larger reserves before doing so). From this increased stability, the insured as well as the fund would be able to profit. More specifically, our main findings are as follows. First, it is deduced that charging remediation measures helps secure the stability of the fund in years following low market returns. Funds in good health can distribute bonuses to their clients while still maintaining their good state. However, this may be detrimental to the utility of the insured since remediation measures may be required afterwards. For these methods to be fully effective, the right choice of parameters is crucial, as our sensitivity analysis shows. Long-lasting periods of low returns have a strong impact on the fund because remediation and bonus measures influence the contributor's payoff.

The remainder of the paper is structured as follows. The second section introduces the model framework and explains the processes that take place. The implementation and choice of parameters are given in the third part. Section 4 covers the numerical analysis. This includes several funding mechanisms and a sensitivity analysis of the results. Additionally, the accounts of the insured at interim time points and capital market scenarios are studied. The final section discusses the results and concludes.

\section{Model Framework}

To properly control for actuarial gains and losses over time, a scenario-based stochastic approach seems natural. By performing numerical simulations, we examine how the accounts of members evolve over time. For this, we look at an individual model contributor in a multi-period setting and take the simplified balance sheet approach comparable to that in Eling and Holder (2013) or Broeders et al. (2011), which is depicted in Figure 1.

\begin{tabular}{l|l} 
Assets & Liabilities \\
\hline Assets $A_{t}$ & Accumulated Contributions $C_{t}$ \\
Remediation measures $K_{t}$ & Bonuses $B_{t}$
\end{tabular}

Figure 1: Simplified balance sheet in time $t$.

The annual contributions of an individual insured in time periods $t=0, \ldots, T$ increase the pension assets $\left(A_{t}\right)$ and lead to a liability changing over time (cf. Figure 2) linked directly to the contributions $\left(C_{t}\right)$. Additional contributions (cf. remediation measures $K_{t}$ introduced below) are accounted to the asset side while bonus payments $\left(B_{t}\right)$ account for the liabilities. We model a pension fund by simulating the assets of the fund limited to an individual contributor. 
The assets follow a stochastic process for the rates of return at time $t$. The liabilities evolve according to the legally fixed minimum interest rate $r_{\mathrm{PL}}$.

For every year that has passed, the fund compares how assets and liabilities relate to each other. This involves looking at the funding ratio $F_{t}=\left(A_{t}+K_{t}\right) /\left(C_{t}+B_{t}\right)$ (Equation 8), which is the key regulatory measure for Swiss pension funds (BVV2, Art. 44). Depending on $F_{t}$ being higher or lower than some predefined threshold, actions are modeled along predefined mechanisms (cf. Sections 2.2 and 3.3).

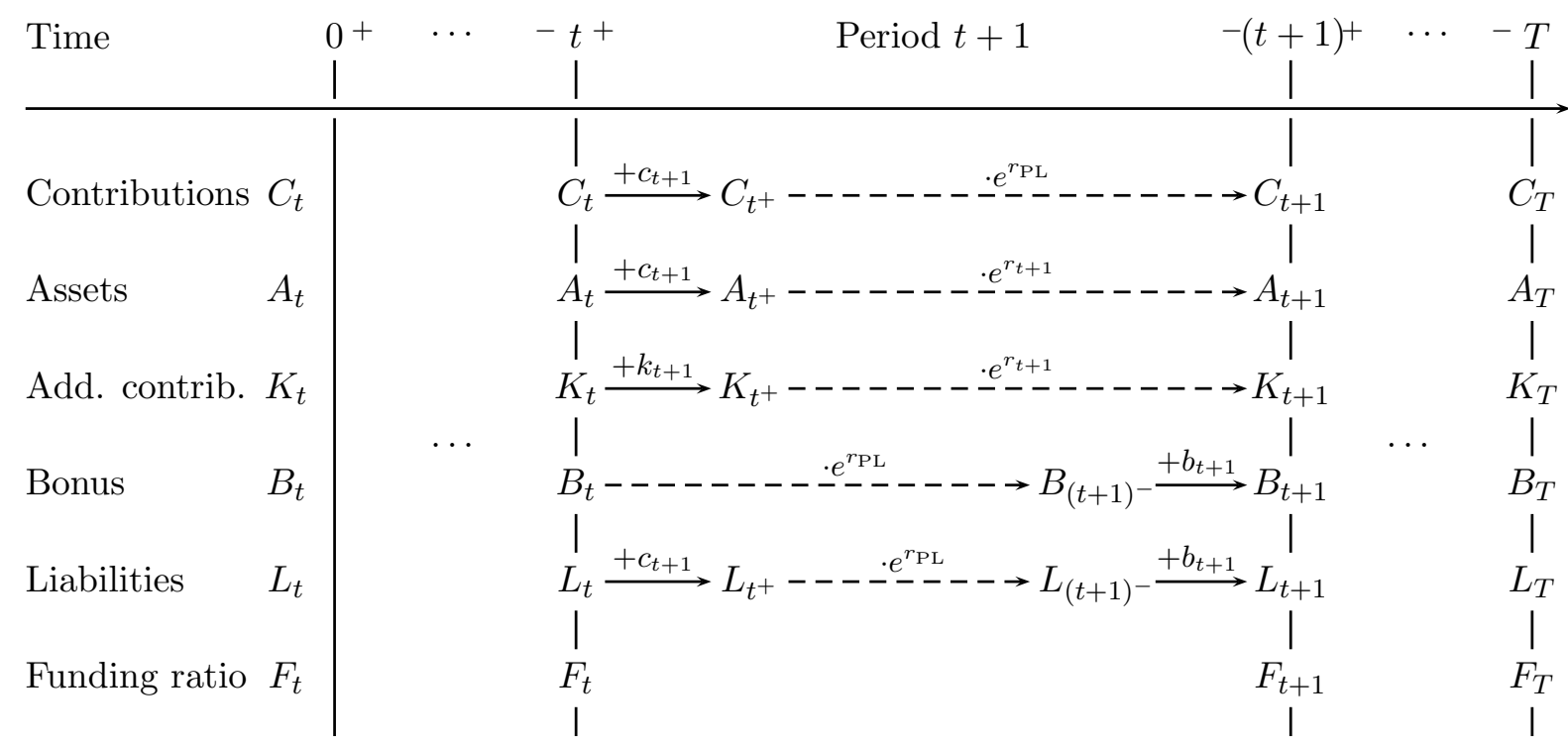

Figure 2: Illustration of the contract variables and the cash flows during the saving period along the contract timeline from time $t=0$ until $T$. In our model $t^{+}$denotes the beginning of period $t+1$ and $(t+1)^{-}$the end of it. Contributions are credited at the beginning of the period $\left(t^{+}\right)$just after the calculation of the funding ratio in $t$. Bonus payments are granted in $(t+1)^{-}$and thereafter the end-of-period funding ratio is evaluated (time $\left.t+1\right)$. For the description of the variables see Sections 2.1 and 2.2.

\subsection{Contributions, Asset Evolution and Funding Ratio}

We consider an active insured at age $x$ contributing during its working time. The time horizon covers the $T$ periods, i.e., times $t=0, \ldots, T$. Adjustments of the key variables occur at the beginning and end of a period, i.e., in $t^{+}$and $(t+1)^{-}$.

Basic Contributions The annual contributions $c_{t}$ depend on the salary and conversion factors linked to the age of the insured. From the salary $S_{t+1}$ in period $t+1$, the coordinated period salary $\hat{S}_{t+1}$ is calculated by subtracting the coordination deduction $S_{t}^{\text {cd }}$. Only the part between a minimum value $\hat{S}_{t}^{\min }$ and a maximum $\hat{S}_{t}^{\max }$ falls under the legal minimum rates (BVG, Art. 8). The coordinated salary in period $t+1, t=0, \ldots, T-1$, is

$$
\hat{S}_{t+1}=\min \left\{\max \left\{S_{t+1}-S_{t}^{\mathrm{cd}} ; \hat{S}_{t}^{\min }\right\} ; \hat{S}_{t}^{\max }\right\} .
$$

The contribution $c_{t+1}$ is determined by multiplication of the coordinated salary $\hat{S}_{t+1}$ with a contribution rate $f_{x, t}^{\mathrm{S}}$, depending on the age $x$ and the time $t=0, \ldots, T-1$ (BVG, Art. 16), i.e.,

$$
c_{t+1}=f_{x, t}^{\mathrm{S}} \cdot \hat{S}_{t+1}
$$


Contributions are assumed to be paid at the beginning of each period, i.e., for period $t+1$, the contribution $c_{t+1}$ is paid at time $t^{+}$. While in practice the payment of $c_{t+1}$ is split up between employees and employers, we do not distinguish the origin of the contributions in our model. The policyholder is assumed to be concerned by the total account value (see also Section 2.3). During every period, the member receives a minimum interest rate $r_{\mathrm{PL}}$ on the sum of its contributions $C_{t}$. The value at time $t+1$ is

$$
C_{t+1}=\left(C_{t}+c_{t+1}\right) \cdot e^{r_{\mathrm{PL}}}
$$

with $C_{0}=0$.

Asset Evolution The assets $A_{t}$ represent the funds that are available for paying the liabilities towards the members. They consist of the paid contributions and the returns from investing them. As for $C_{t}, c_{t+1}$ is added to the assets at the beginning of each period, i.e.,

$$
A_{t^{+}}=A_{t}+c_{t+1}
$$

with $A_{0}=0$. The fund must be self-financing with the contributions and capital market earnings. To simulate the return from the capital market, a basic stock model is applied. We use a geometric Brownian motion with drift $\mu_{\mathrm{B}}$ and volatility $\sigma_{\mathrm{B}}$, i.e.,

$$
d A_{t}=\mu_{\mathrm{B}} A_{t} d t+\sigma_{\mathrm{B}} A_{t} d W_{t}
$$

where $W=\left(W_{t}\right)_{t \geq 0}$ is a standard Brownian motion (Björk, 2004). The return in period $t+1$, then, is

$$
r_{t+1}=\ln \left[\frac{A_{t+1}}{A_{t}^{+}}\right]=\mu_{\mathrm{B}}-\frac{\sigma_{\mathrm{B}}^{2}}{2}+\sigma_{\mathrm{B}} \cdot N_{0,1},
$$

with $N_{0,1}$ a standard normally distributed random variable. At the end of the period, the assets $A_{t+1}$ are

$$
A_{t+1}=A_{t^{+}} \cdot e^{r_{t+1}}=\left(A_{t}+c_{t+1}\right) \cdot e^{r_{t+1}} .
$$

Funding Ratio The funding ratio is determined by dividing the total assets, i.e., equity and additional contributions over the liabilities. Additional contributions may be due in case of periods with underfunding (cf. Section 2.2). The funding ratio therefore is

$$
F_{t+1}=\frac{A_{t+1}+K_{t+1}}{L_{t+1}}=\frac{A_{t+1}+K_{t+1}}{C_{t+1}+B_{t+1}}
$$

where the liabilities $L_{t+1}$ equal the contributions $C_{t+1}$ and surpluses $B_{t+1}$. Bonuses are distributed when the fund is in good health (cf. Section 2.2.2).

The funding ratio is calculated at the end of period $t+1$. Depending on its value, it is decided whether bonuses can be distributed or whether additional contributions need to be charged. A value below $100 \%$ corresponds to underfunding, while $F_{t+1}>100 \%$ means overfunding.

\subsection{Monitoring of the Funding Ratio and Funding Mechanisms}

When the funding ratio exceeds a certain threshold, the surpluses can be distributed to the members. In the case of underfunding, remediation measures may be necessary. The concept of using boundaries for the funding ratio, that we apply therein, has been discussed earlier by, 
e.g., Gerber and Shiu (2003). In the following, the corresponding mechanisms, that are used in our analysis, are explained. ${ }^{3}$

\subsubsection{Situation of Underfunding and Additional Contributions}

We consider a procedure that automatically determines recovery contributions. In practice this is not an automated process. The board of the fund evaluates the underfunding with consideration of the fund's overall situation (e.g., market environment, investment portfolio, characteristics of the members). If recovery measures have been decided upon, the employers of the insured may also be involved in covering deficits (BVG, Art. 65d).

Once $F_{t}$ drops below $100 \%$, the assets do not suffice to meet the obligations. Therefore, the insured may be requested to pay additional contributions. Additional contributions are paid at the beginning of the following year. We present two methods for calculating the additional contributions $k_{t+1}$ in period $t+1$.

Our first method (UF1) is based on a share $z$ of the funding gap $L_{t}-\left(A_{t}+K_{t}\right)$. This comes into action once the funding ratio drops below a limit $F_{\min }$. Additional contributions at time $t^{+}$ then are

$$
k_{t+1}=z \cdot\left(L_{t}-\left(A_{t}+K_{t}\right)\right),
$$

where $z$ represents the share of $L_{t}-\left(A_{t}+K_{t}\right)$ to be paid.

The second method (UF2) is based on a Value-at-Risk approach. ${ }^{4}$ Here, $k_{t+1}$ is set such that at the end of the next period, the funding ratio falls below $100 \%$ only with probability $q$. The probability $q$ is typically a small number. In the Solvency II regulation for private insurances, for example, $q$ is set to $0.5 \%$. In our sensitivity analyses, we use a $1 \%$ to $10 \%$ one-year underfunding probability threshold (see Table 3 ). In our model, realizations of the funding ratio are evaluated through

$$
\hat{F}_{t+1}\left(k_{t+1}\right)=\frac{\left(A_{t}+c_{t+1}\right) \cdot e^{r_{t+1}}+\left(K_{t}+k_{t+1}\right) \cdot e^{r_{t+1}}}{\left(L_{t}+c_{t+1}\right) \cdot e^{r_{\mathrm{PL}}}},
$$

where $r_{t+1}$ is a realization of the asset return in the following period. Thus, additional contributions $k_{t+1}$ must fulfill the equation

$$
\operatorname{VaR}_{1-q}\left(1-\hat{F}_{t+1}\right)=\inf \left\{x \mid \mathbb{P}\left(\hat{F}_{t+1}\left(k_{t+1}\right)<100 \%-x\right) \leq q\right\} \stackrel{!}{=} 0,
$$

\footnotetext{
${ }^{3}$ In contrast to life insurance companies, regulations such as Solvency II and the Swiss Solvency Test (SST) do not apply to Swiss pension funds. The reason why a transfer of these regulations has not been performed yet can be found in the differences between funds and insurers. In contrast to insurance companies, gains and losses are distributed among the members. Additionally, the contractual relationship between the policyholder and the pension fund is quite rigid.For example, employees are automatically affiliated in the pension plan connected to the employer. Due to these characteristics, a temporary phase of underfunding can be dealt with. Pension funds stay in business and pursue their investment strategies even when they are underfunded. Also, it is the decision of the board of the fund if, and to what extent, remediation measures and surplus payments are to be made. This stands in strong contrast to life insurance companies regulated by market authorities that require strict solvency calculations and adequate capitalization on a year-to-year basis. While there have been efforts to suggest regulations comparable to Solvency II and the SST for pension funds (see, e.g. Schweizerische Kammer der Pensionskassen-Experten, 2012; Braun et al., 2011), there are currently no regulations with respect to this.

${ }^{4}$ Note that in practice, the use of method (UF1) is more common among Swiss pension funds. Furthermore, it is the board of the fund that ultimately decides on when charging remediation measures as well as on their amount.
} 
with $\stackrel{!}{=}$ denoting that the Value-at-Risk has to be equal to zero. Thus, the equation

$$
\inf \left\{x \mid \mathbb{P}\left(\frac{\left(A_{t}+c_{t+1}\right) \cdot e^{r_{t+1}}+\left(K_{t}+k_{t+1}\right) \cdot e^{r_{t+1}}}{\left(L_{t}+c_{t+1}\right) \cdot e^{r_{\mathrm{PL}}}}<100 \%-x\right) \leq q\right\}=0
$$

needs to be solved numerically for $k_{t+1} \cdot{ }^{5}$ The intuition behind this is that higher additional contributions $k_{t+1}$ increase the funding ratio and decrease the ruin probability, i.e., the probability that the funding ratio falls below $100 \%$ in the next period. We therefore aim to find the smallest value for $k_{t+1}$ for which the probability that the funding ratio falls below $100 \%(x \stackrel{!}{=} 0)$ is smaller or equal to a small value $q$. The contributions $k_{t+1}$ are added to the assets, but not to the account of the insured. Because $K_{t}$ is invested on the capital market, the return in period $t+1$ is $r_{t+1}$. We have

$$
K_{t+1}=K_{t^{+}} \cdot e^{r_{t+1}}=\left(K_{t}+k_{t+1}\right) \cdot e^{r_{t+1}}
$$

\subsubsection{Situation of Overfunding and Surplus Distribution}

In years where market returns exceed $r_{\mathrm{PL}}$, the assets of the pension fund grow. Part of the surplus can be distributed to the members (BVG, Art. 68a). Additionally, it is required that the fund holds a reserve in case of fluctuation of the assets (BVV2, Art. 48e). Therefore, we assume for our base scenario (see, e.g., the cases shaded in gray in our sensitivity analysis, Table 3) that surpluses can only be distributed once a certain reserve on the liabilities has been accumulated (see the definition of the parameters in Table 1 and Footnote 11 in Section 3.3). We assume that a bonus $b_{t+1}$ is paid out at the end of a period if $F_{(t+1)^{-}}$exceeds a limit $F_{t+1}^{\mathrm{L}} \cdot{ }^{6}$ Because it represents an obligation, the sum of surpluses $B_{t+1}$ is part of the liabilities. Such payments cause a drop of the funding ratio. We assume that $b_{t+1}$ is chosen such that from the threshold $F_{t+1}^{\mathrm{L}}$, the decrease equals $\Delta F_{t+1}$. Subsequently, $b_{t+1}$ is derived from

$$
F_{t+1}=\frac{A_{t+1}+K_{t+1}}{C_{t+1}+B_{(t+1)^{-}}+b_{t+1}} \stackrel{!}{=} F_{t+1}^{\mathrm{L}}-\Delta F_{t+1}
$$

The bonuses $B_{t}$ grow with the rate $r_{\mathrm{PL}}$ and their value at time $t+1$ is

$$
B_{t+1}=B_{(t+1)^{-}}+b_{t+1}=B_{t} \cdot e^{r_{\mathrm{PL}}}+b_{t+1} .
$$

While in our model $B_{t}$ increases with a rate of $r_{\mathrm{PL}}$, this is not required in practice, as bonuses do not fall under the legal minimum (see, e.g., Avanzi and Purcal (2014)). In the above, we assume that surpluses are paid out as a lump sum. In practice, it is more common to assign bonuses as increased interest rates on the insured's account. The methods can be converted into each other, i.e.,

$$
L_{t+1}=\left(L_{t}+c_{t+1}\right) \cdot e^{r_{\mathrm{PL}}}+b_{t+1} \equiv\left(L_{t}+c_{t+1}\right) \cdot e^{r_{\mathrm{PL}}+r_{\mathrm{b}}}=\left(L_{t}+c_{t+1}\right) \cdot e^{r_{\mathrm{eff}}},
$$

with

$$
r_{\mathrm{eff}}=r_{\mathrm{PL}}+r_{\mathrm{b}} \geq r_{\mathrm{PL}} .
$$

In our discussion, we focus on the lump sum payments.

\footnotetext{
${ }^{5}$ For solving Equation 12, we use a numerical root-finding algorithm. A reliable and quick method is, e.g., the method proposed by Brent (1974).

${ }^{6}$ This can be compared with the dividend distribution analyzed in Avanzi et al. (2016).
} 


\subsection{Contributor Valuation}

To evaluate the payoff and utility of the members, we use several indicators. To assess the contributor's return on its contributions, we use the internal rate of return $r_{c+b+k}$ defined as follows: If the insured were only to receive the return $r_{c+b+k}$ on its regular contributions, the account value would equal the value of contributions and bonuses minus remediation measures at time $T$, i.e.,

$$
\sum_{t=1}^{T} c_{t} \cdot e^{r_{c+b+k} \cdot(T-t+1)} \stackrel{!}{=} C_{T}+B_{T}-K_{T} .
$$

To measure the utility, we use the certainty equivalent $u^{-1}\left(\mathbb{E}\left[u\left(L_{T}\right)\right]\right)$. For this, we use a constant relative risk aversion utility as introduced, e.g., in Broeders et al. (2011),

$$
u(x)=\frac{x^{1-\rho}}{1-\rho}, \text { with } \rho>0, \rho \neq 1 .
$$

In order to take the amounts paid in the various cases (regular contributions and irregular remediation measures) into account in our analysis, we focus on the relative certainty equivalent given by

$$
\frac{u^{-1}\left(\mathbb{E}\left[u\left(L_{T}\right)\right]\right)}{C_{T}+\mathbb{E}\left[K_{T}\right]}
$$

\section{Implementation and Parameterization}

To simulate the course of the assets we use Monte Carlo simulations. Results are obtained using $N=100000$ realizations in every period. We first introduce a reference case setting with the starting values for the various model parameters. The parameters are summarized in Table 1 and described in the following.

\subsection{Legislation}

We consider one type of insured working from age 25 until retirement at 65 , corresponding to $T=40$ working years. Their salary starts at CHF 55000 (first period) and grows linearly to CHF 82300 (present value), corresponding to the Swiss average at time zero. Additionally, the salary grows with a rate of $r_{\mathrm{S}}=1 \%$ per year in order to reflect the increase of salaries related to the increase of prices. ${ }^{7}$ The pension fund contributions are set by the legislator. The coordination deduction $S_{0}^{\text {cd }}$ for 2016 is CHF 24675. The minimum and maximum coordinated salaries $\hat{S}_{0}^{\text {min }}$ and $\hat{S}_{0}^{\text {max }}$ are CHF 3525 and CHF 59925 (BVV2, Art. 5). They are adapted over time with the rate $r_{\mathrm{S}}$. The contribution factor $f_{x, t}^{\mathrm{S}}$ changes with the age of the contributor. We consider total contributions, i.e. the factors correspond to the contributions by employers and employees. ${ }^{8}$ Since the salary $S_{t}$ and the contribution rates $f_{x, t}^{\mathrm{S}}$ grow with age and time, $c_{t}$ is higher in later years. For 2016, the minimum interest rate $r_{\mathrm{PL}}$ is $1.25 \%$ (BVV2, Art. 12). We first use this as a constant value as we do for the distribution of the capital market returns, since the general interest environment remains unchanged. When studying the capital market scenarios in Section 4.4, we allow for variations in $r_{\mathrm{PL}}$, though (see also Footnote 12). For the risk-free interest rate $r_{\mathrm{f}}$, a value of $1 \%$ is chosen. This is related to $r_{\mathrm{S}}$, the increase in prices.

\footnotetext{
${ }^{7}$ This corresponds to the historical salary changes also found in the adaptations of the BVV2 salary boundaries.

${ }^{8}$ In our analysis, we do not differentiate between the sources of the contributions, but we focus on the total payoff at time $T$.
} 


\begin{tabular}{|c|c|c|}
\hline Parameter & Variable & Value \\
\hline Number of periods & $T$ & 40 \\
\hline \multicolumn{3}{|l|}{ Legislation } \\
\hline Coordination deduction (at time $t=0$ ) & $S_{0}^{\mathrm{cd}}$ & CHF 24675 \\
\hline Minimum coordinated salary $(t=0)$ & $\hat{S}_{0}^{\min }$ & CHF 3525 \\
\hline Maximum coordinated salary $(t=0)$ & $\hat{S}_{0}^{\max }$ & CHF 59925 \\
\hline Total contribution rate of age class $25-34$ & $f_{x, t}^{\mathrm{S}}$ & $7 \%$ \\
\hline Total contribution rate of age class $35-44$ & $f_{x, t}^{\mathrm{S}}$ & $10 \%$ \\
\hline Total contribution rate of age class $45-54$ & $f_{x, t}^{\mathrm{S}}$ & $15 \%$ \\
\hline Total contribution rate of age class $55-65$ & $f_{x, t}^{\mathrm{S}}$ & $18 \%$ \\
\hline Salary growth rate & $r_{\mathrm{S}}$ & $1 \%$ \\
\hline Minimum interest rate & $r_{\mathrm{PL}}$ & $1.25 \%$ \\
\hline Risk-free interest rate & $r_{\mathrm{f}}$ & $1 \%$ \\
\hline \multicolumn{3}{|l|}{ Capital market } \\
\hline Drift of the geometric Brownian motion process & $\mu_{B}$ & $3.0 \%$ \\
\hline Volatility of the geometric Brownian motion process & $\sigma_{B}$ & $6.0 \%$ \\
\hline \multicolumn{3}{|l|}{ Pension fund governance } \\
\hline Minimum funding ratio & $F_{\min }$ & $100 \%$ \\
\hline Proportion of missing assets to be paid & $z$ & $90 \%$ \\
\hline Quantile for additional contributions & $q$ & $1 \%$ \\
\hline Upper bound for distributing surpluses & $F_{t+1}^{\mathrm{L}} \equiv F^{\mathrm{L}}$ & $110 \%$ \\
\hline Difference of bonus bounds & $\Delta F_{t+1} \equiv \Delta F$ & $2 \%$ \\
\hline \multicolumn{3}{|l|}{ Policyholder utility } \\
\hline Risk aversion & $\rho$ & 30 \\
\hline
\end{tabular}

Table 1: Input parameters for the reference case.

It follows that $\sum_{t=1}^{40} c_{t} / \sum_{t=1}^{40} \hat{S}_{t}$ is constant and equals $13.71 \%$. When no bonuses are paid, a fixed value for $r_{\mathrm{PL}}$ leads to constant liabilities at retirement, i.e. $L_{40}=361212$.

\subsection{Capital Market}

To calibrate the parameters of the asset process, the LPP-40 sub-index of the Pictet LPP 2000 index is utilized. With an equity portion of $40 \%$, this index is close to the average investments of larger pension funds in Switzerland. It also contains approximately $40 \%$ of foreign currency investments. ${ }^{9}$ We parametrize a geometric Brownian motion based on the annualized average monthly performance from January 2000 to December 2015, i.e., we calculate the index performance using monthly data and choose the (rounded) annualized values of $\mu_{\mathrm{B}}=3 \%$ for the drift and $\sigma_{\mathrm{B}}=6 \%$ for the volatility. ${ }^{10}$

\footnotetext{
${ }^{9}$ The composition of the index is $60 \%$ bonds and $40 \%$ equities, with about $40 \%$ of the investments made in foreign currencies. For further information, see https://www.group.pictet/corporate/en/home/institutiona 1_investors/lpp_indices/lpp2000.html, September 2016.

${ }^{10}$ We chose to use annualized values based on the monthly observations to have a larger statistical basis (192 observations). The annualized expected return is calculated from the monthly expected return by multiplying by 12 . The corresponding volatility is obtained from multiplication by $\sqrt{12}$. For comparison, when calculating the performance on the base of the only 16 annual data points, we find that the expected return remains unchanged and yields $3 \%$ while the volatility is about $2 \%$ higher in the considered period.
} 


\subsection{Pension Fund Governance and Policyholder Utility}

If $F_{t}$ falls below $F_{\min }$, the fund can ask for remediation measures. In the reference case, we use a lower limit of $F_{\min }=100 \%$ (legal minimum). For our first method, a proportion $z=90 \%$ of $L_{t}-A_{t}$ is used. The purpose of this is to reduce the one-time capital outlay for the policyholders and spread the remediation expenses over a longer time. The second method is based on a Value-at-Risk approach. The additional payment $k_{t}$ is set such that in the following period, the fund is underfunded with a probability of $q=1 \%$. Once the funding ratio exceeds $F_{t+1}^{\mathrm{L}}$, a bonus can be distributed. We use a constant upper limit of $F_{t+1}^{\mathrm{L}} \equiv F^{\mathrm{L}}=110 \%^{11}$ and assume that surpluses are distributed until the funding ratio has decreased to $F^{\mathrm{L}}-\Delta F=108 \%$, corresponding to $\Delta F_{t+1} \equiv \Delta F=2 \%$. In the policyholder utility, we use a risk aversion factor of $\rho=30$.

\section{Numerical Analysis and Discussion}

\subsection{Funding Mechanisms: Impact over Time}

We assess the impact of remediation measures and surplus distributions by analyzing $F_{t}, k_{t}$ and $b_{t}$ for

- case (A), with neither additional contributions nor surplus distribution,

- case (B), with only additional contributions, and

- case (C), with both remediation measures and surplus distribution.

The additional contributions are calculated along method (UF1). The parameters are as in Table 1.

Funding Ratios and Remediation Measures In Figure 3, the 1\%, 50\% and 99\% quantiles of $F_{t}$ are given for the cases (A) and (B). In Figure 3(a) (case A), the $1 \%$ quantile of $F_{t}$ always stays below $100 \%$. It starts at approximately $90 \%$ and subsequently drops to about $80 \%$. The $50 \%$ quantile $q_{50 \%}\left(F_{t}\right)$ starts at almost $100 \%$ and grows to about $130 \%$ in $t=40$. This drift is related to the difference between $\mu_{B}$ and $r_{\mathrm{PL}}$. In case (B), in Figure 3(b), the additional contributions only affect the $1 \%$ quantile, now reaching almost $100 \%$ in $T$. Remediation measures lead to an improvement of underfunding situations, while the other quantiles remain unchanged. The $99 \%$ quantile grows from nearly $120 \%$ to $220 \%$ making the distribution of surpluses possible.

Expected Remediation Measures For case (B), Figure 4 shows the development of $k_{t}$ and $K_{t}$. Figure $4(\mathrm{a})$ shows the expected present value of $k_{t}$ and the $99 \%$ quantile. The $99 \%$ quantile of the additional contributions grows and reach more than CHF 10000 at time $T$. The present expected value stays close to zero. As in Figure 3, the fund is always overfunded in the upper $50 \%$ of all cases.

For the present value of $K_{t}$ (see Figure 4(b)), we observe that the $99 \%$ quantile reaches about CHF 50000. The shape of the $q_{99 \%}\left(K_{t} \cdot e^{-(t-1) r_{\mathrm{f}}}\right)$ curve follows from the additional

\footnotetext{
${ }^{11}$ In our base case, bonuses can only be distributed if the funding ratio exceeds $110 \%$, i.e. when reserves of $10 \%$ on top of the value of the liabilities are accumulated. This reference scenario corresponds to the target values mostly observed in practice ( $5 \%$ to $10 \%$ ). In our sensitivity analysis, we vary $F^{\mathrm{L}}=110 \%$ through very low and high values ranging from $102 \%$ to $118 \%$ corresponding to reserves of $2 \%$ to $18 \%$ of the liabilities (see Table 3 ).
} 


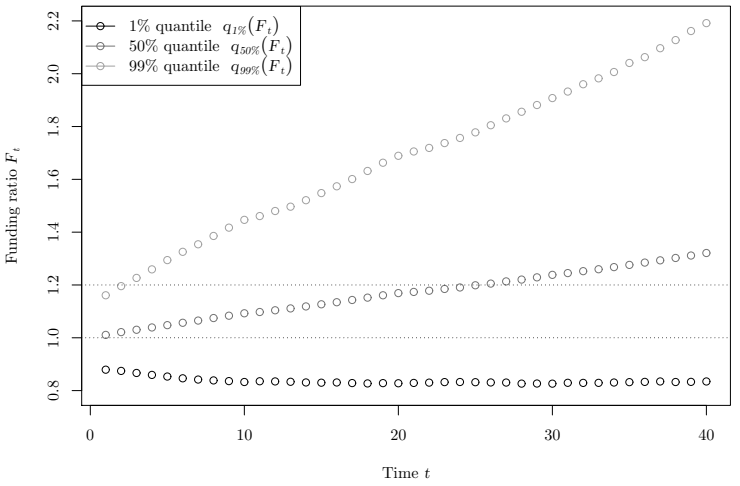

(a) Quantiles of the funding ratio $F_{t}$ in case $(\mathrm{A})$

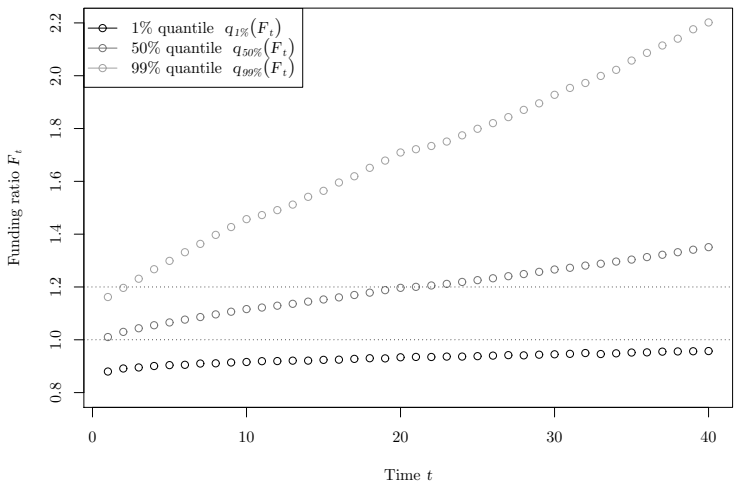

(b) Quantiles of the funding ratio $F_{t}$ in case (B)

Figure 3: Illustration of the funding ratio $F_{t}$ in the cases $\mathrm{A}$ (no additional contributions, no bonus payments) and $\mathrm{B}$ (additional contributions, no bonus payments). The graphs depict the $1 \%, 50 \%$ and $99 \%$ quantiles of $F_{t}$. The parameters are as in the reference case given in Table 1.

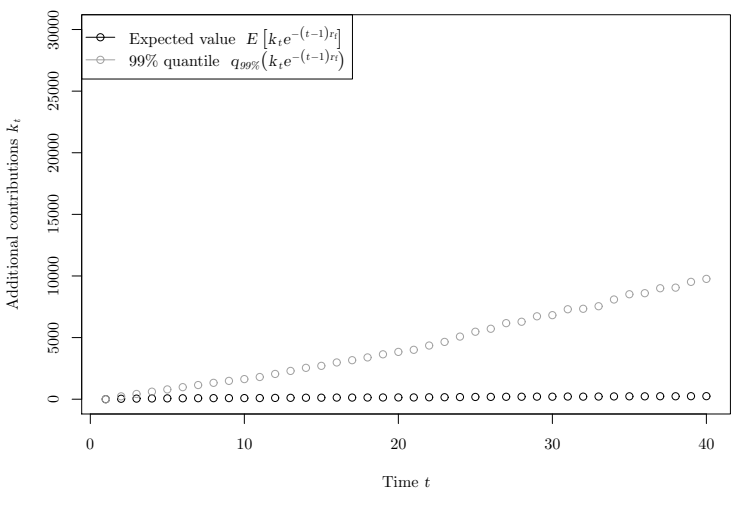

(a) Present value and $99 \%$ quantile of the additional contributions $k_{t}$ in case (B)

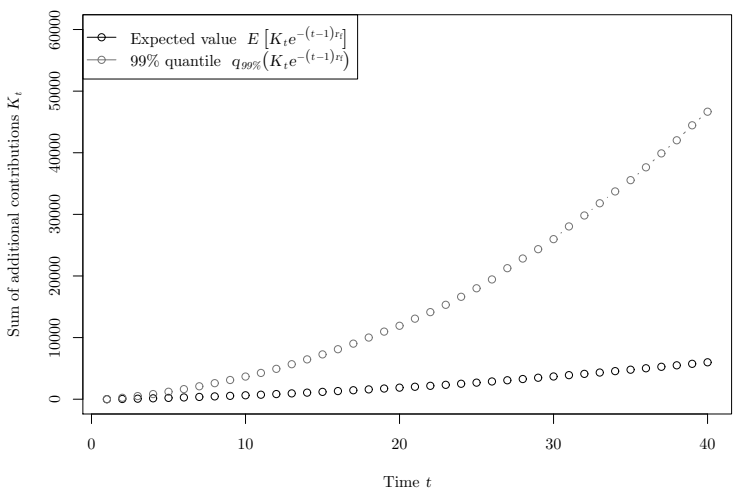

(b) Present value and $99 \%$ quantile of the sum of additional contributions $K_{t}$ in case (B)

Figure 4: Illustration of the discounted remediation measures $k_{t}$ and their sum $K_{t}$ in case B (additional contributions, no bonus payments). The graphs depict the expected present value and the $99 \%$ quantile of $k_{t}$ and $K_{t}$. The parameters are as in the reference case in Table 1.

contributions being credited with the returns $r_{t+1}$. The expected value exceeds zero (see line 7 in Table 3 from the sensitivity analysis in Section 4.2). The expected remediation measures discounted to time zero $\mathbb{E}\left[k_{t} \cdot e^{-(t-1) r_{\mathrm{f}}} \mid k_{t}>0\right]$ amount to CHF 1520 . They are levied four times on average (cf. Table 3). The overall expected payments are approximately CHF 6080 .

Surplus Distribution For case (C), Figure 5 depicts the 1\%, 50\% and $99 \%$ quantiles of $F_{t}$ from periods 1 to 40 . Distributing surpluses leads to the $1 \%$ quantile $q_{1 \%}\left(F_{t}\right)$ being around $90 \%$. The $99 \%$ quantile $q_{99 \%}\left(F_{t}\right)$ lies at $110 \%$, which equals $F^{\mathrm{L}}$. The $50 \%$ quantile $q_{50 \%}\left(F_{t}\right)$ starts at approximately $100 \%$ and converges to about $107 \%$ (below $F^{\mathrm{L}}-\Delta F=110 \%-2 \%=108 \%$ ).

Additional Contributions and Bonus Payments Figure 6 depicts the expected present value and the $99 \%$ quantile of $k_{t}$ and $b_{t}$. The expected present value of $k_{t}$ exceeds CHF 3000 at time $T$, whereas $b_{t}$ reaches approximately CHF 8000 . The surpluses that are paid out on average are thus approximately double of what needs to be paid in remediation cases. A similar conclu- 


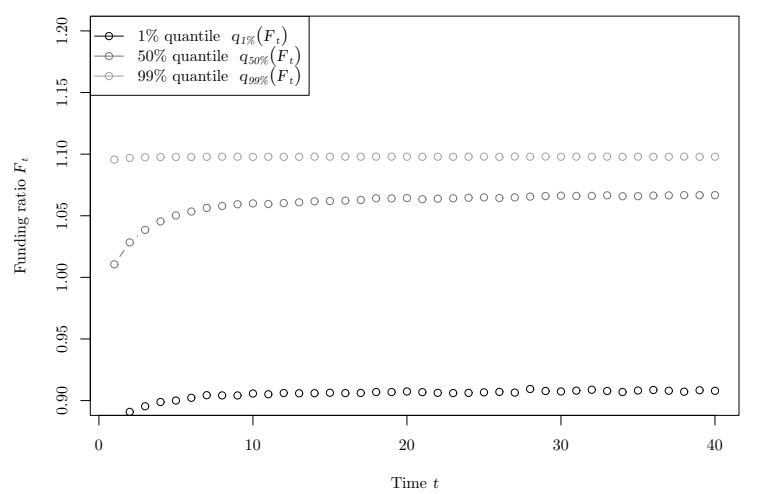

Figure 5: Illustration of the funding ratio $F_{t}$ in case (C) (additional contributions, bonus payments). The graph depicts the $1 \%, 50 \%$ and $99 \%$ quantiles of $F_{t}$. The parameters are as in the reference case given in Table 1.

sion can be drawn for the quantile values where the surpluses of best cases are twice the value of remediation measures. Due to the drift of the investment process, they increase exponentially. In $T, \mathbb{E}\left[k_{t} \cdot e^{-(t-1) r_{\mathrm{f}}}\right]$ reaches almost CHF 250 while $\mathbb{E}\left[b_{t} \cdot e^{-t r_{\mathrm{f}}}\right]$ is about CHF 10000 . This matches the observations made regarding the funding ratio where $q_{50 \%}\left(F_{t}\right)$ is around $107 \%$. With the given bonus bounds, $\mu_{\mathrm{B}}=3 \%$ and $r_{\mathrm{PL}}=1.25 \%$, the fund is likely to be overfunded, i.e. $b_{t}$ grows faster than $k_{t}$. This causes higher volatility in the payout stream, i.e., despite bonuses in some years, additional contributions need to be made in others (cf. discussion in Section 4.2).

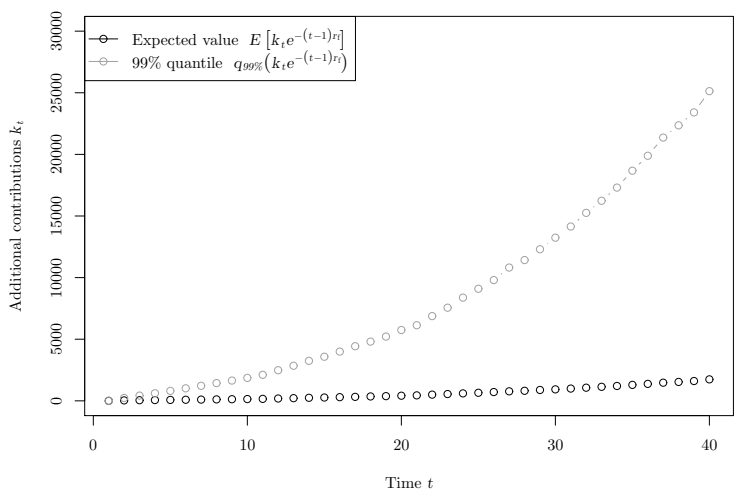

(a) Present value and $99 \%$ quantile of the additional contributions $k_{t}$ in case $(\mathrm{C})$

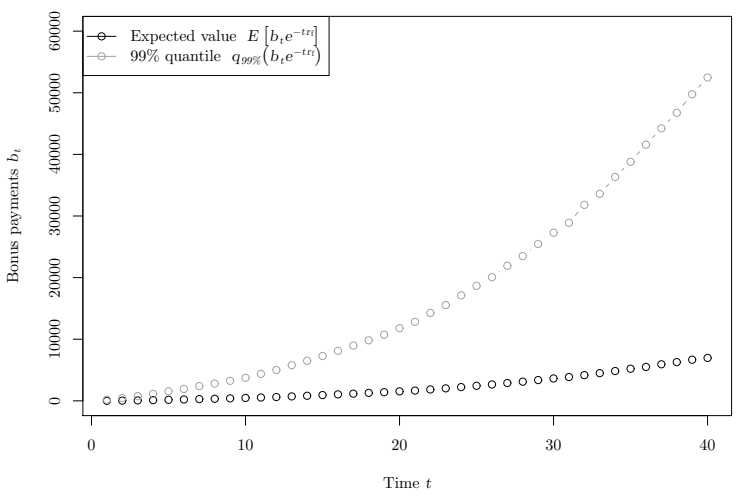

(b) Present value and $99 \%$ quantile of the bonus payments $b_{t}$ in case $(\mathrm{C})$

Figure 6: Illustration of the discounted extra contributions $k_{t}$ and the bonus payments $b_{t}$ in case $\mathrm{C}$ (additional contributions, bonus payments). The graphs depict the expected present value as well as the $99 \%$ quantile of $k_{t}$ and $b_{t}$. The parameters are as in the reference case given in Table 1.

\subsection{Sensitivity Analysis}

We study key indicators at time $T=40$ from the contributor's and the fund's perspectives and analyze how sensitive the results are to parameter changes. In Table 3 , the columns labeled 1 to 7 contain the input values, columns 8 to 13 the insured's perspective, 14 to 19 the funding levels and 20 to 25 the surplus distribution and the remediation measures. A detailed explanation of 
the columns is given in Table 2 .

In the first line of Table 3, case (A) with neither remediation measures nor surplus distributions is analyzed. Rows 2 to 11, show case (B) with additional contributions. This includes changing $F_{\min }$ for method (UF1) and $q$ for (UF2). Lines 12 to 32 cover case (C) with remediation measures and bonus payments. There, $F^{\mathrm{L}}$ is altered first. Next, we vary the difference of bonus bounds $\Delta F$. Subsequently, the parameters $F_{\min }$ and $q$ are changed as for case (B). When changing one variable, the others are kept constant (cf. Table 1).

\begin{tabular}{|c|c|c|}
\hline & Item & Description \\
\hline 1 & Case & $\begin{array}{l}\text { (A) no additional contributions, no bonus payments, (B) } \\
\text { only additional contributions, (C) additional contributions } \\
\text { and bonus payments (Section } 4.1 \text { ) }\end{array}$ \\
\hline 2 & UF (indicator) & $\begin{array}{l}\text { Calculation method for remediation measures: } 1=\text { percent- } \\
\text { age of funding ratio, } 2=\text { Value-at-Risk approach (Section } \\
2.2 .1 \text { ) }\end{array}$ \\
\hline 3 & $F_{\min }$ & Minimum funding ratio targeted (Equation 8) \\
\hline 4 & $q$ & $\begin{array}{l}\text { Probability for the funding ratio to fall below } 100 \% \text { within } \\
\text { one year (Equation 11) }\end{array}$ \\
\hline 5 & Bonus (indicator) & $\begin{array}{l}\text { Use of surplus distribution: } 0=\text { no bonus payments, } 1= \\
\text { bonus is distributed (Section } 2.2 .2 \text { ) }\end{array}$ \\
\hline 6 & $F^{\mathrm{L}}$ & Upper bound for distributing bonus (Equation 14) \\
\hline 7 & $\Delta F$ & Difference of bonus bounds (Equation 14) \\
\hline 8 & $\mathbb{E}\left[L_{40}\right]$ & Expected liabilities in $t=40$ \\
\hline 9 & $\frac{\sigma\left[L_{40}\right]}{\mathbb{E}\left[L_{40}\right]}$ & Relative volatility of $L_{40}$ \\
\hline 10 & $\gamma\left[L_{40}\right]$ & Skewness of $L_{40}$ \\
\hline 11 & $u^{-1}\left(\mathbb{E}\left[u\left(L_{40}\right)\right]\right)$ & Certainty equivalent in $t=40$ (Equation 19) \\
\hline 12 & $\frac{u^{-1}\left(\mathbb{E}\left[u\left(L_{40}\right)\right]\right)}{C_{40}+\mathbb{E}\left[K_{40}\right]}$ & Relative certainty equivalent in $t=40$ \\
\hline 13 & $\mathbb{E}\left[r_{c+b+k}\right]$ & Internal rate of return (Equation 18) \\
\hline 14 & $\mathbb{E}\left[F_{t}\right]$ & Expected funding ratio \\
\hline 15 & $\mathbb{E}\left[q_{1 \%}\left(F_{t}\right)\right]$ & Expected $1 \%$ quantile of the funding ratio \\
\hline 16 & $\mathbb{E}\left[q_{50 \%}\left(F_{t}\right)\right]$ & Expected $50 \%$ quantile of the funding ratio \\
\hline 17 & $\mathbb{E}\left[q_{99 \%}\left(F_{t}\right)\right]$ & Expected $99 \%$ quantile of the funding ratio \\
\hline 18 & $q_{1 \%}\left(\sum_{t=1}^{40} \mathbb{1}_{\left\{F_{t}<1\right\}}\right)$ & $1 \%$ quantile of the number of years in underfunding \\
\hline 19 & $q_{50 \%}\left(\sum_{t=1}^{40} \mathbb{1}_{\left\{F_{t}>F^{L}\right\}}\right)$ & $50 \%$ quantile of the number of years with $F_{t}$ exceeding $F^{\mathrm{L}}$ \\
\hline 20 & $\frac{\mathbb{E}\left[\sum_{t=1}^{40} k_{t} \cdot e^{-(t-1) r_{\mathrm{f}}}\right]}{\sum_{t=1}^{40} c_{t} \cdot e^{-(t-1) r_{\mathrm{f}}}}$ & $\begin{array}{l}\text { Ratio of the expected present sum of additional contribu- } \\
\text { tions over the sum of present regular contributions }\end{array}$ \\
\hline 21 & $\mathbb{E}\left[\sum_{t=1}^{40} \mathbb{1}_{\left\{k_{t}>0\right\}}\right]$ & $\begin{array}{l}\text { Expected number of years with remediation measures } \\
\text { required }\end{array}$ \\
\hline
\end{tabular}




$$
\begin{array}{ll}
22 & \mathbb{E}\left[k_{t} \cdot e^{-(t-1) r_{\mathrm{f}}} \mid k_{t}>0\right] \\
23 & \frac{\mathbb{E}\left[\sum_{t=1}^{40} b_{t} \cdot e^{-t r_{\mathrm{f}}}\right]}{\sum_{t=1}^{40} c_{t} \cdot e^{-(t-1) r_{\mathrm{f}}}} \\
24 & \mathbb{E}\left[\sum_{t=1}^{40} \mathbb{1}_{\left\{b_{t}>0\right\}}\right] \\
25 & \mathbb{E}\left[b_{t} \cdot e^{-t r_{\mathrm{f}}} \mid b_{t}>0\right]
\end{array}
$$

Expected present value of remediation measures when required

Ratio of the expected present sum of distributed surpluses over the sum of present regular contributions

Expected number of years with surpluses required

Expected present value of distributed surpluses when required

Table 2: Description of the items in Table 3.

Impact of Minimum Funding Ratio $\boldsymbol{F}_{\text {min }}$ For case (A), the mean of the effective return $\mathbb{E}\left[r_{c+b+k}\right]$ in column 13 (Table 3 ) equals the minimum interest rate $r_{\mathrm{PL}}=1.25 \%$. Introducing remediation measures according to (UF1) in case (B) leads to higher overall payments. Since $k_{t}$ is not credited to the liabilities, $\mathbb{E}\left[r_{c+b+k}\right]$ decreases from $1.16 \%$ for a lower boundary of $F_{\min }$ equal to $90 \%$ down to $1.10 \%$ for $F_{\min }=100 \%$. For the additional contributions, a lower value for $F_{\min }$ leads to fewer remediation payments (column 21). The average amount $k_{t}$ paid is highest for a low value of $F_{\min }$ and decreases as the boundary is raised (column 22). Column 20 contains the ratio $\mathbb{E}\left[\sum_{t=1}^{40} k_{t} \cdot e^{-(t-1) r_{\mathrm{f}}}\right] / \sum_{t=1}^{40} c_{t} \cdot e^{-(t-1) r_{\mathrm{f}}}$ : lower values of $F_{\min }$ lead to lower additional contributions, ranging from $2.6 \%$ for $F_{\min }=100 \%$ to $1.5 \%$ for $F_{\min }=90 \%$. While there are considerable changes in the amount and frequency of additional contributions, $\mathbb{E}\left[F_{t}\right]$ is nearly constant at approximately 1.20 .

Value-At-Risk Approach For the Value-at-Risk approach (UF2) in case (B), the sensitivity is more important. The remediation measures resulting from $1-q$ increasing from $90 \%$ up to $99 \%$ are higher than for (UF1). Columns 21 and 22 show that additional contributions are more frequent. The payments remain at a similar level as for high values of $F_{\text {min }}$. The $\mathbb{E}\left[\sum_{t=1}^{40} k_{t} \cdot e^{-(t-1) r_{\mathrm{f}}}\right] / \sum_{t=1}^{40} c_{t} \cdot e^{-(t-1) r_{\mathrm{f}}}$ ratio goes up to $8 \%$. Due to the increased contributions, $F_{t}$ increases too. With $q$ decreasing from $10 \%$ to $1 \%$, the mean of $F_{t}$ grows from 1.24 to 1.29 .

Impact of the Upper Distribution Limit $\boldsymbol{F}^{\mathbf{L}}$ In case (C), significantly higher effective returns are observed. Changing $F^{\mathrm{L}}$ from $102 \%$ to $118 \%$ leads to fewer bonus payments (column 24). Since bonuses on average decrease by more than CHF 1000 , the ratio of bonuses over conributions $\mathbb{E}\left[\sum_{t=1}^{40} b_{t} \cdot e^{-t r_{\mathrm{f}}}\right] / \sum_{t=1}^{40} c_{t} \cdot e^{-(t-1) r_{\mathrm{f}}}$ decreases too. Meanwhile, the amount and the frequency of additional contributions decrease. For $\mathbb{E}\left[r_{c+b+k}\right]$, a higher threshold for surplus distributions leads to a decrease. Overall, $\mathbb{E}\left[F_{t}\right]$ rises together with $F^{\mathrm{L}}$.

Bonus Bounds $\boldsymbol{\Delta} \boldsymbol{F}$ As seen in columns 23 to 25 , increasing $\Delta F$ from 0.01 to 0.06 leads to a strong increase in average bonuses. While the expected number of payments decreases, a growth of about $25 \%$ take place in $\mathbb{E}\left[\sum_{t=1}^{40} b_{t} \cdot e^{-t r_{\mathrm{f}}}\right] / \sum_{t=1}^{40} c_{t} \cdot e^{-(t-1) r_{\mathrm{f}}}$. Due to larger amounts being distributed, remediation measures become higher and more frequent. The expected return $\mathbb{E}\left[r_{c+b+k}\right]$ and the certainty equivalent $u^{-1}\left(\mathbb{E}\left[u\left(L_{40}\right)\right]\right)$ increase. While $\Delta F=0.01$ leads to a certainty equivalent that equals approximately CHF 420000 , a change to $\Delta F=0.06$ leads to an increase in $u^{-1}\left(\mathbb{E}\left[u\left(L_{40}\right)\right]\right)$ of about CHF 14000 . 
Insured Perspective When raising the upper bound for distributing bonuses $F^{\mathrm{L}}$, the certainty equivalent $u^{-1}\left(\mathbb{E}\left[u\left(L_{40}\right)\right]\right.$ ) decreases together with $\mathbb{E}\left[r_{c+b+k}\right]$ by more than $20 \%$ (Table 3 , lines $12-16)$. Insureds should thus prefer lower values of $F^{\mathrm{L}}$, coming along with regular bonus payments. This is supported by the relative certainty equivalent being the highest for $F^{\mathrm{L}}=102 \%$. Contrary movements follow from varying $\Delta F$. While $u^{-1}\left(\mathbb{E}\left[u\left(L_{40}\right)\right]\right)$ grows together with it, the relative certainty equivalent (column 12) decreases by approximately $5 \%$. This is due to higher bonus payments causing an increased need for remediation measures in years with lower market returns.

In fact, policyholders should prefer that no bonuses are distributed, as can be seen in Figure 7. In this, the relative certainty equivalent is depicted depending on the difference of bonus bounds $\Delta F$ and the upper boundary for distributing bonuses $F^{\mathrm{L}}$ in case $\mathrm{C}$ with $F_{\min }=100 \%$. The different colors correspond to the values of the relative certainty equivalent $u^{-1}\left(\mathbb{E}\left[u\left(L_{40}\right)\right]\right)$. In this, darker colors represent a higher relative certainty equivalent and lighter ones a lower one. As the graph shows, the influence of $F^{\mathrm{L}}$ is bigger than that of $\Delta F$ as the changes when moving horizontally on the graph are much larger than the ones when moving vertically. This is consistent with the results of the sensitivity analysis in Table 3 (lines $12-22$ ). Overall, it can be seen that the relative certainty equivalent is larger for smaller values of the upper bound $F^{\mathrm{L}}$. Therefore, policyholders should prefer that no bonuses are distributed, as this gives them the highest relative certainty equivalent. It can thus be said, that the common belief of clients profiting from surplus distributions is a fallacy. As we can see, the benefit from keeping additional funds as protection against times with lower capital market returns, is higher than the one from distributing them to the insureds. Pension funds should therefore put more stress on accumulating reserves rather than distributing funds to their clients.

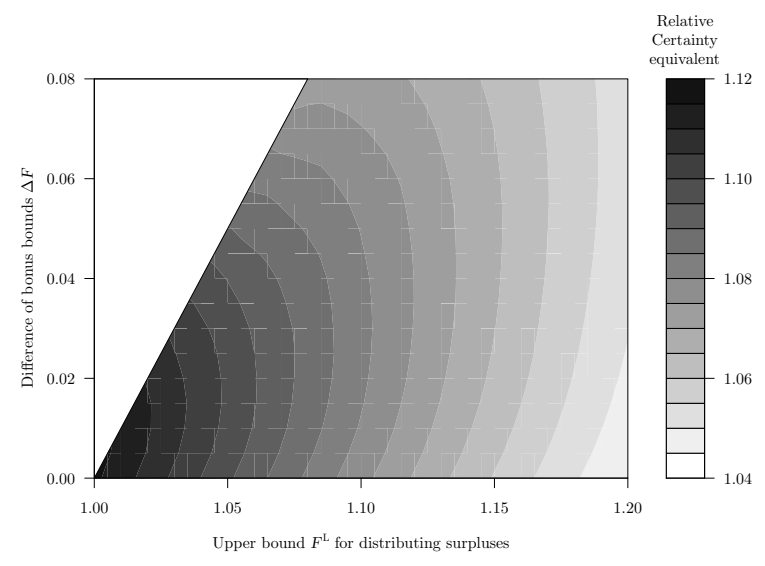

Figure 7: Illustration of the relative certainty equivalent depending on the difference of bonus bounds $\Delta F$ and the upper bound $F^{\mathrm{L}}$ for distributing bonuses.

Impact of Remediation Measures on Surpluses Varying $F_{\min }$, the changes for the additional contributions $k_{t}$ correspond to case (B). With an increasing value for $F_{\text {min }}$, additional payments become lower but more frequent. Consequently, the ratio of additional over regular contributions $\mathbb{E}\left[\sum_{t=1}^{40} k_{t} \cdot e^{-(t-1) r_{\mathrm{f}}}\right] / \sum_{t=1}^{40} c_{t} \cdot e^{-(t-1) r_{\mathrm{f}}}$ increases with a higher threshold $F_{\min }$ inducing an increase in $\mathbb{E}\left[L_{40}\right]$. Bonuses are, on average, distributed at approximately 1.3 more points in time. Together with an increase of $\mathbb{E}\left[b_{t} \cdot e^{-t r_{\mathrm{f}}} \mid b_{t}>0\right]$ by approximately $2 \%, \mathbb{E}\left[\sum_{t=1}^{40} b_{t} \cdot e^{-t r_{\mathrm{f}}}\right] / \sum_{t=1}^{40} c_{t} \cdot e^{-(t-1) r_{\mathrm{f}}}$ grows by nearly $15 \%$ from one extreme to the other. For the Value-at-Risk approach, we see that for low values of $q$, both $k_{t}$ and $b_{t}$ grow 
considerably. For $q=2.5 \%, \mathbb{E}\left[\sum_{t=1}^{40} b_{t} \cdot e^{-t r_{\mathrm{f}}}\right] / \sum_{t=1}^{40} c_{t} \cdot e^{-(t-1) r_{\mathrm{f}}}$ exceeds $150 \%$. The remediation measures grow similarly, reaching a ratio of approximately $249.1 \%$ for $q=1 \%$. This follows from the additional contributions causing a rise of the funding ratio. Subsequently, $F_{t}$ often exceeds $F^{\mathrm{L}}$ and the additional contributions are redistributed as bonuses, leading to an increase in the certainty equivalent of approximately $80 \%$. As the relative certainty equivalent drops down to almost $70 \%$ though, this is unfavorable for insureds.

\subsection{Interim Valuation}

In today's working environment, employees change their jobs more frequently than before (see Cosandey, 2014). Often this is linked to a change of the pension fund associated with the employer. For the fund, remediation is most important. If contributors leave, they are entitled by law to receive their regular contributions and the minimum interest rate that has been paid. Remediation measures are only credited to the assets $A_{t}$ but not to the accounts and remain with the fund. For our model, bonuses are credited to the accounts of the policyholders and therefore remain with the insured when leaving. Exceptions may apply, though, in the case of a partial liquidation (see, e.g., FZG, Art. 23), where bonuses could be canceled by required remediation measures. We examine the results after 10 years (insured aged 35) and 20 years (age 45) and compare them with the ones at retirement for the scenarios (A), (B) and (C). Numerical results are reported in Table 4.

Valuation at Time $\boldsymbol{t}=\mathbf{1 0}$ For cases (B) and (C) in $t=10, \mathbb{E}\left[K_{t}\right]$ stays below CHF 1000. Since $C_{t}$ is no more than CHF 25000 at that time, this can be considered a low amount. Compared to $t=40$, less than $10 \%$ of $\mathbb{E}\left[K_{t}\right]$ is paid in the first ten years in case (B). Introducing surpluses in (C) leads to a small increase of the remediation measures. Simultaneously, the ratio of the expected sums of additional contributions in $t=10$ and 40 decreases to less than $3 \%$ (0.85 vs. 32.10). The bonuses lead to a growth in the expected liabilities of more than CHF 2000 , more than twice the amount of the remediation measures. The ratio $\mathbb{E}\left[L_{t}\right] /\left(C_{t}+\mathbb{E}\left[K_{t}\right]\right)$ grows and is lager than one. The same holds for $u^{-1}\left(\mathbb{E}\left[u\left(L_{t}\right)\right]\right) /\left(C_{t}+\mathbb{E}\left[K_{t}\right]\right)$. The distribution of surpluses also leads to higher remediation measures and to a higher volatility causing the relative certainty equivalent to be almost $5 \%$ lower than $\mathbb{E}\left[L_{t}\right] /\left(C_{t}+\mathbb{E}\left[K_{t}\right]\right)(1.008$ vs. 1.054).

Valuation at Time $\boldsymbol{t}=\mathbf{2 0}$ In case (B), $\mathbb{E}\left[K_{t}\right]$ exceeds CHF 2000, corresponding to an increase by a factor of three (against 670 in $t=10)$. They reach approximately $30 \%(2.11$ vs. 7.69) of the value in $t=40$. Distributing surpluses increases $\mathbb{E}\left[K_{t}\right]$. While it doubles, the ratio of $\mathbb{E}\left[K_{t}\right]$ for $t=20$ and 40 decreases to less than $15 \%$ (4.18 vs. 32.10 ). The distribution of bonuses leads to the expected liabilities gaining approximately CHF 15000 . This is more than six times larger than in time $t=10$ (15 vs. 2.3). Thus, while the remediation measures increase, the distributed bonuses increase even more. This also holds for $\mathbb{E}\left[L_{t}\right] /\left(C_{t}+\mathbb{E}\left[K_{t}\right]\right)$ which grows by approximately $7 \%$ (1.129 vs. 1.054). In case (B), it stays at 0.974 . The relative certainty equivalent experiences a gain of more than $2 \%(1.032$ vs. 1.008) in case (C) and is smaller than $\mathbb{E}\left[L_{t}\right] /\left(C_{t}+\mathbb{E}\left[K_{t}\right]\right)$.

Discussion In early years, the paid amounts remain rather low. As the salary and the conversion factor grow over time, most of the contributions are paid towards the end of the time frame. The required amounts in the case of underfunding remain low in early years. Consequently, when changing pension funds in early years, the effect of contributors not taking 


\begin{tabular}{|c|c|c|c|c|c|c|c|c|c|c|c|c|c|}
\hline & \multicolumn{7}{|c|}{ Cases and parameters } & \multicolumn{6}{|c|}{ Valuation of final payoff in $T$ and effective returns } \\
\hline & 1 & 2 & 3 & 4 & 5 & 6 & 7 & 8 & 9 & 10 & 11 & 12 & 13 \\
\hline & $\begin{array}{l}0 \\
\tilde{J} \\
\tilde{J} \\
\tilde{J}\end{array}$ & 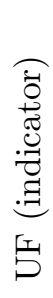 & 者 & $\begin{array}{l}\widehat{a} \\
. 尹 \\
\text { or }\end{array}$ & 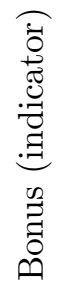 & 宝 & ¿ & 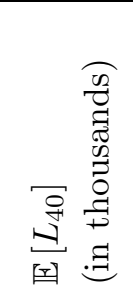 & 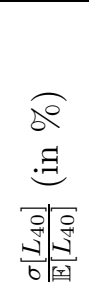 & \begin{tabular}{l}
$\underset{\mathrm{F}}{\mathrm{H}}$ \\
\multicolumn{1}{c}{}
\end{tabular} & 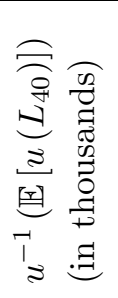 & 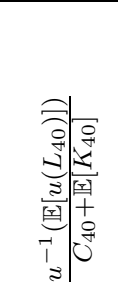 & 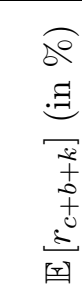 \\
\hline 1 & $\mathrm{~A}$ & & & & & & & 361.2 & 0 & & 361.2 & 1.000 & 1.25 \\
\hline 2 & $\mathrm{~B}$ & 1 & 0.90 & & 0 & & & 361.2 & 0 & & 361.2 & 0.988 & 1.16 \\
\hline 3 & $\mathrm{~B}$ & 1 & 0.92 & & 0 & & & 361.2 & 0 & & 361.2 & 0.986 & 1.15 \\
\hline 4 & B & 1 & 0.94 & & 0 & & & 361.2 & 0 & & 361.2 & 0.983 & 1.13 \\
\hline 5 & B & 1 & 0.96 & & 0 & & & 361.2 & 0 & & 361.2 & 0.981 & 1.12 \\
\hline 6 & B & 1 & 0.98 & & 0 & & & 361.2 & 0 & & 361.2 & 0.980 & 1.11 \\
\hline 7 & B & 1 & 1.00 & & 0 & & & 361.2 & 0 & & 361.2 & 0.979 & 1.10 \\
\hline 8 & B & 2 & & 10.0 & 0 & & & 361.2 & 0 & & 361.2 & 0.961 & 0.96 \\
\hline 9 & B & 2 & & 5.0 & 0 & & & 361.2 & 0 & & 361.2 & 0.954 & 0.90 \\
\hline 10 & B & 2 & & 2.5 & 0 & & & 361.2 & 0 & & 361.2 & 0.948 & 0.85 \\
\hline 11 & B & 2 & & 1.0 & 0 & & & 361.2 & 0 & & 361.2 & 0.938 & 0.76 \\
\hline 12 & $\mathrm{C}$ & 1 & 1.00 & & 1 & 1.02 & 0.02 & 623.9 & 15.0 & 0.80 & 504.6 & 1.100 & 3.37 \\
\hline 13 & $\mathrm{C}$ & 1 & 1.00 & & 1 & 1.06 & 0.02 & 544.3 & 15.1 & 0.93 & 450.7 & 1.089 & 2.99 \\
\hline 14 & $\mathrm{C}$ & 1 & 1.00 & & 1 & 1.10 & 0.02 & 501.7 & 15.2 & 1.04 & 423.2 & 1.076 & 2.74 \\
\hline 15 & $\mathrm{C}$ & 1 & 1.00 & & 1 & 1.14 & 0.02 & 475.0 & 15.1 & 1.13 & 407.0 & 1.063 & 2.54 \\
\hline 16 & $\mathrm{C}$ & 1 & 1.00 & & 1 & 1.18 & 0.02 & 455.7 & 14.9 & 1.22 & 396.4 & 1.050 & 2.36 \\
\hline 17 & $\mathrm{C}$ & 1 & 1.00 & & 1 & 1.10 & 0.01 & 495.2 & 15.1 & 1.06 & 419.8 & 1.075 & 2.69 \\
\hline 18 & $\mathrm{C}$ & 1 & 1.00 & & 1 & 1.10 & 0.02 & 501.7 & 15.2 & 1.04 & 423.2 & 1.076 & 2.74 \\
\hline 19 & $\mathrm{C}$ & 1 & 1.00 & & 1 & 1.10 & 0.03 & 508.3 & 15.3 & 1.01 & 426.2 & 1.076 & 2.78 \\
\hline 20 & $\mathrm{C}$ & 1 & 1.00 & & 1 & 1.10 & 0.04 & 514.8 & 15.4 & 0.99 & 429.0 & 1.074 & 2.82 \\
\hline 21 & $\mathrm{C}$ & 1 & 1.00 & & 1 & 1.10 & 0.05 & 521.6 & 15.5 & 0.96 & 431.6 & 1.072 & 2.86 \\
\hline 22 & $\mathrm{C}$ & 1 & 1.00 & & 1 & 1.10 & 0.06 & 528.6 & 15.7 & 0.93 & 434.0 & 1.068 & 2.90 \\
\hline 23 & $\mathrm{C}$ & 1 & 0.90 & & 1 & 1.10 & 0.02 & 483.7 & 15.6 & 1.10 & 409.9 & 1.088 & 2.74 \\
\hline 24 & $\mathrm{C}$ & 1 & 0.92 & & 1 & 1.10 & 0.02 & 487.4 & 15.5 & 1.09 & 412.9 & 1.086 & 2.73 \\
\hline 25 & $\mathrm{C}$ & 1 & 0.94 & & 1 & 1.10 & 0.02 & 491.5 & 15.4 & 1.08 & 415.9 & 1.083 & 2.73 \\
\hline 26 & $\mathrm{C}$ & 1 & 0.96 & & 1 & 1.10 & 0.02 & 496.0 & 15.3 & 1.06 & 419.2 & 1.080 & 2.73 \\
\hline 27 & $\mathrm{C}$ & 1 & 0.98 & & 1 & 1.10 & 0.02 & 499.9 & 15.2 & 1.05 & 421.9 & 1.077 & 2.74 \\
\hline 28 & $\mathrm{C}$ & 1 & 1.00 & & 1 & 1.10 & 0.02 & 501.7 & 15.2 & 1.04 & 423.2 & 1.076 & 2.74 \\
\hline 29 & $\mathrm{C}$ & 2 & & 10.0 & 1 & 1.10 & 0.02 & 581.9 & 14.7 & 0.88 & 479.2 & 1.044 & 2.87 \\
\hline 30 & $\mathrm{C}$ & 2 & & 5.0 & 1 & 1.10 & 0.02 & 685.0 & 16.2 & 0.83 & 534.7 & 0.991 & 3.09 \\
\hline 31 & $\mathrm{C}$ & 2 & & 2.5 & 1 & 1.10 & 0.02 & 903.2 & 19.3 & 0.86 & 635.8 & 0.888 & 3.43 \\
\hline 32 & $\mathrm{C}$ & 2 & & 1.0 & 1 & 1.10 & 0.02 & 1430.6 & 23.2 & 0.90 & 854.3 & 0.742 & 4.04 \\
\hline
\end{tabular}

Table 3: Valuation of final payoff and effective returns in cases (A), (B) and (C) (see Section 4.1). The parameter values are as in Table 1. 


\begin{tabular}{|c|c|c|c|c|c|c|c|c|c|c|c|c|}
\hline & \multicolumn{12}{|c|}{ Funding levels, bonuses and additional contributions } \\
\hline & 14 & 15 & 16 & 17 & 18 & 19 & 20 & 21 & 22 & 23 & 24 & 25 \\
\hline & 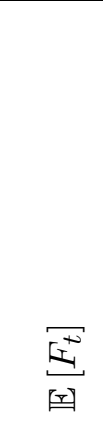 & 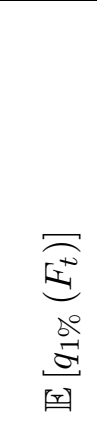 & 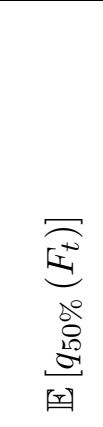 & 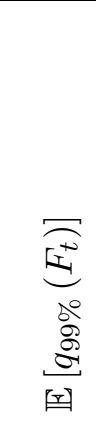 & 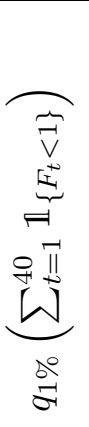 & 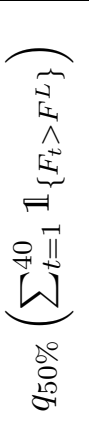 & 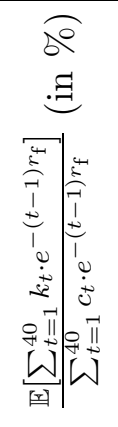 & 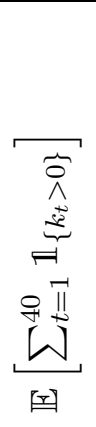 & 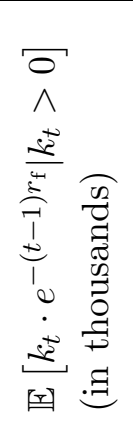 & 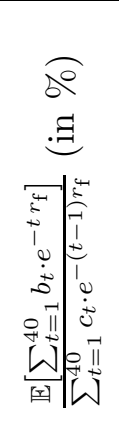 & 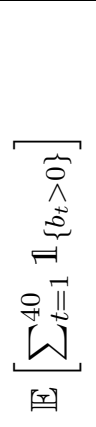 & 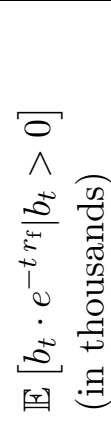 \\
\hline 1 & 1.17 & 0.84 & 1.14 & 1.57 & 0 & 25 & & & & & & \\
\hline 2 & 1.19 & 0.90 & 1.15 & 1.58 & 0 & 26 & 1.5 & 0.5 & 6.41 & & & \\
\hline 3 & 1.19 & 0.90 & 1.15 & 1.58 & 0 & 26 & 1.8 & 0.8 & 5.01 & & & \\
\hline 4 & 1.20 & 0.91 & 1.16 & 1.58 & 0 & 26 & 2.0 & 1.2 & 3.87 & & & \\
\hline 5 & 1.20 & 0.92 & 1.16 & 1.58 & 0 & 27 & 2.3 & 1.8 & 2.93 & & & \\
\hline 6 & 1.20 & 0.93 & 1.16 & 1.58 & 0 & 27 & 2.5 & 2.7 & 2.16 & & & \\
\hline 7 & 1.20 & 0.93 & 1.16 & 1.58 & 0 & 27 & 2.6 & 4.0 & 1.52 & & & \\
\hline 8 & 1.24 & 0.98 & 1.19 & 1.61 & 0 & 31 & 4.9 & 6.6 & 1.74 & & & \\
\hline 9 & 1.26 & 1.00 & 1.21 & 1.62 & 0 & 33 & 5.8 & 7.4 & 1.84 & & & \\
\hline 10 & 1.27 & 1.01 & 1.22 & 1.63 & 0 & 35 & 6.7 & 8.1 & 1.94 & & & \\
\hline 11 & 1.29 & 1.03 & 1.24 & 1.65 & 0 & 36 & 8.0 & 8.9 & 2.11 & & & \\
\hline$\overline{12}$ & 0.98 & 0.88 & 1.00 & 1.02 & 10 & 19 & 31.0 & 15.6 & 4.64 & 73.7 & 18.8 & 9.14 \\
\hline 13 & 1.01 & 0.90 & 1.03 & 1.05 & 4 & 15 & 16.8 & 10.9 & 3.60 & 51.4 & 14.7 & 8.14 \\
\hline 14 & 1.04 & 0.91 & 1.05 & 1.09 & 1 & 11 & 10.3 & 7.9 & 3.04 & 39.4 & 11.6 & 7.91 \\
\hline 15 & 1.07 & 0.91 & 1.07 & 1.12 & 0 & 9 & 7.0 & 6.2 & 2.64 & 31.9 & 9.4 & 7.92 \\
\hline 16 & 1.09 & 0.92 & 1.09 & 1.15 & 0 & 7 & 5.2 & 5.2 & 2.33 & 26.6 & 7.7 & 8.03 \\
\hline 17 & 1.05 & 0.91 & 1.06 & 1.09 & 1 & 12 & 9.4 & 7.4 & 2.94 & 37.6 & 12.6 & 6.96 \\
\hline 18 & 1.04 & 0.91 & 1.05 & 1.09 & 1 & 11 & 10.3 & 7.9 & 3.04 & 39.4 & 11.6 & 7.91 \\
\hline 19 & 1.04 & 0.90 & 1.05 & 1.09 & 2 & 11 & 11.2 & 8.3 & 3.13 & 41.3 & 10.8 & 8.94 \\
\hline 20 & 1.03 & 0.90 & 1.05 & 1.09 & 2 & 10 & 12.2 & 8.8 & 3.23 & 43.1 & 10.0 & 10.04 \\
\hline 21 & 1.03 & 0.90 & 1.04 & 1.09 & 2 & 9 & 13.2 & 9.3 & 3.33 & 45.0 & 9.4 & 11.20 \\
\hline 22 & 1.03 & 0.90 & 1.03 & 1.09 & 3 & 9 & 14.4 & 9.7 & 3.45 & 47.0 & 8.8 & 12.43 \\
\hline 23 & 1.03 & 0.87 & 1.04 & 1.09 & 1 & 10 & 5.0 & 1.0 & 11.21 & 34.4 & 10.3 & 7.78 \\
\hline 24 & 1.03 & 0.88 & 1.05 & 1.09 & 1 & 10 & 6.1 & 1.5 & 9.17 & 35.4 & 10.6 & 7.81 \\
\hline 25 & 1.04 & 0.89 & 1.05 & 1.09 & 1 & 11 & 7.3 & 2.3 & 7.37 & 36.6 & 10.9 & 7.84 \\
\hline 26 & 1.04 & 0.90 & 1.05 & 1.09 & 1 & 11 & 8.6 & 3.5 & 5.77 & 37.8 & 11.2 & 7.87 \\
\hline 27 & 1.04 & 0.90 & 1.05 & 1.09 & 1 & 11 & 9.8 & 5.2 & 4.33 & 38.9 & 11.5 & 7.90 \\
\hline 28 & 1.04 & 0.91 & 1.05 & 1.09 & 1 & 11 & 10.3 & 7.9 & 3.04 & 39.4 & 11.6 & 7.91 \\
\hline 29 & 1.06 & 0.94 & 1.07 & 1.09 & 0 & 17 & 31.2 & 16.8 & 4.34 & 61.9 & 16.7 & 8.67 \\
\hline 30 & 1.06 & 0.96 & 1.09 & 1.09 & 0 & 21 & 57.0 & 37.5 & 3.54 & 90.9 & 20.7 & 10.24 \\
\hline 31 & 1.07 & 0.98 & 1.11 & 1.11 & 0 & 26 & 112.7 & 39.0 & 6.74 & 152.3 & 25.4 & 13.96 \\
\hline 32 & 1.07 & 1.00 & 1.13 & 1.13 & 0 & 31 & 249.1 & 39.0 & 14.89 & 301.0 & 30.7 & 22.89 \\
\hline
\end{tabular}

Table 3: Valuation of final payoff and effective returns in cases (A), (B) and (C) (see Section 4.1). The parameter values are as in Table 1 (continued). 


\begin{tabular}{|c|c|c|c|c|c|c|c|c|c|}
\hline & 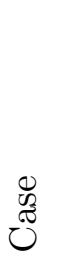 & 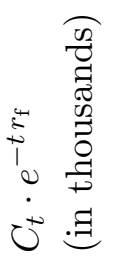 & 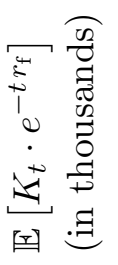 & 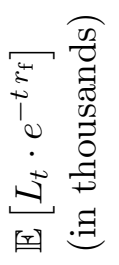 & 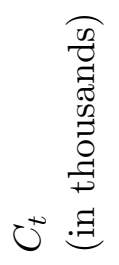 & 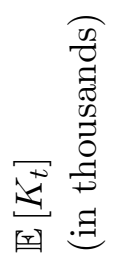 & 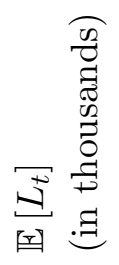 & 氛新 & 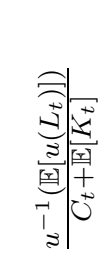 \\
\hline \multirow[t]{3}{*}{$t=10$} & $\mathrm{~A}$ & 23.8 & 0 & 23.8 & 26.3 & 0 & 26.3 & 1 & 1 \\
\hline & B & 23.8 & 0.61 & 23.8 & 26.3 & 0.67 & 26.3 & 0.975 & 0.975 \\
\hline & $\mathrm{C}$ & 23.8 & 0.77 & 25.9 & 26.3 & 0.85 & 28.6 & 1.054 & 1.008 \\
\hline \multirow[t]{3}{*}{$t=20$} & $\bar{A}$ & 65.4 & 0 & 65.4 & 79.9 & 0 & 79.9 & 1 & 1 \\
\hline & B & 65.4 & 1.73 & 65.4 & 79.9 & 2.11 & 79.9 & 0.974 & 0.974 \\
\hline & $\mathrm{C}$ & 65.4 & 3.43 & 77.7 & 79.9 & 4.18 & 94.9 & 1.129 & 1.032 \\
\hline \multirow[t]{3}{*}{$t=40$} & $\mathrm{~A}$ & 242.1 & 0 & 242.1 & 361.2 & 0 & 361.2 & 1 & 1 \\
\hline & B & 242.1 & 5.16 & 242.1 & 361.2 & 7.69 & 361.2 & 0.979 & 0.979 \\
\hline & $\mathrm{C}$ & 242.1 & 21.52 & 336.3 & 361.2 & 32.10 & 501.7 & 1.276 & 1.076 \\
\hline
\end{tabular}

Table 4: Simulation results for cases (A), (B) and (C) after 10, 20 and 40 years. The parameter values are as in Table 1.

remediation measures with themselves remains fairly low. Distributing surpluses increases the relative certainty equivalent.

\subsection{Impact of Capital Market Scenarios}

Focusing on case $(\mathrm{C})$, we analyze capital market scenarios. We consider the reference case and let the drift $\mu_{B}$ follow a predefined path using two scenarios. In the first one, $\mu_{B}$ equals the reference value in the first five periods. This is followed by ten periods with high returns of $5 \%$ (i.e. $2 \%$ increase). Subsequently, it drops to $1 \%$ for another ten periods (mimicking a crisis and a post-crisis environment, see e.g. Europe after the 2008 financial crisis). For the last five time points it returns to $3 \%$. For scenario two, the course of $\mu_{B}$ is mirrored. The minimum interest rate $r_{\mathrm{PL}}$ follows $\mu_{B}$ at a ratio of $r_{\mathrm{PL}} / \mu_{B}=1.25 / 3=41.67 \%$ with a delay of two years. This simulates a delayed adaptation of $r_{\mathrm{PL}}$, reflecting practice, e.g., in Switzerland, where the minimum interest rate is adapted through a political process (BVG, Art. 15) ${ }^{12}$ The paths of $\mu_{B}$ and $r_{\mathrm{PL}}$ for both scenarios are depicted in Figure 8.

Simulation Results Table 5 reports the results. Figures 9 to 11 illustrate the development of the means of $F_{t}, k_{t}$ and $b_{t}$. The periods of increased and decreased drift $\mu_{\mathrm{B}}$ are shown as light and dark gray areas, respectively.

Funding Ratio $\boldsymbol{F}_{\boldsymbol{t}}$ From Figure 9(a) it can be seen that during the times of increased market returns, the funding ratio increases sharply. From approximately $101 \%$, it rises to more than $105 \%$. The decrease of $\mu_{\mathrm{B}}$ has an immediate impact on $F_{t}$ which falls below $103 \%$. As in the case of high returns, $F_{t}$ converges quickly to this value and subsequently changes only little. The recovery of $\mu_{\mathrm{B}}$ to $3 \%$ at the end of the time frame also leads to the funding ratio returning to $104 \%$. It can be seen in Table 5 that, as in the reference case, $\mathbb{E}\left[F_{t}\right]$ equals $104 \%$.

\footnotetext{
${ }^{12}$ In the Swiss system, a commission regularly decides about changes of $r_{\mathrm{PL}}$. For this, they take the market conditions into account by using a rolling average of government bonds as a benchmark. We mirror this process in our analysis by adjusting the guaranteed interest rate $r_{\mathrm{PL}}$ with a delay of two years at a fixed ratio of $r_{\mathrm{PL}} / \mu_{B}$.
} 


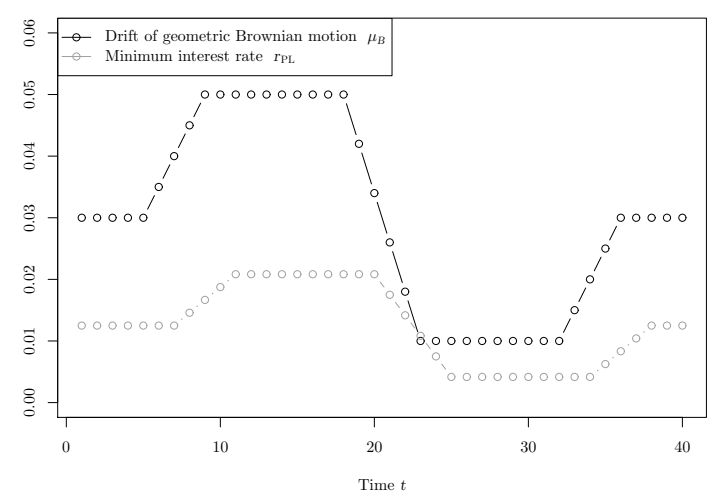

(a) $\mu_{B}$ and $r_{\mathrm{PL}}$ for Scenario 1 .

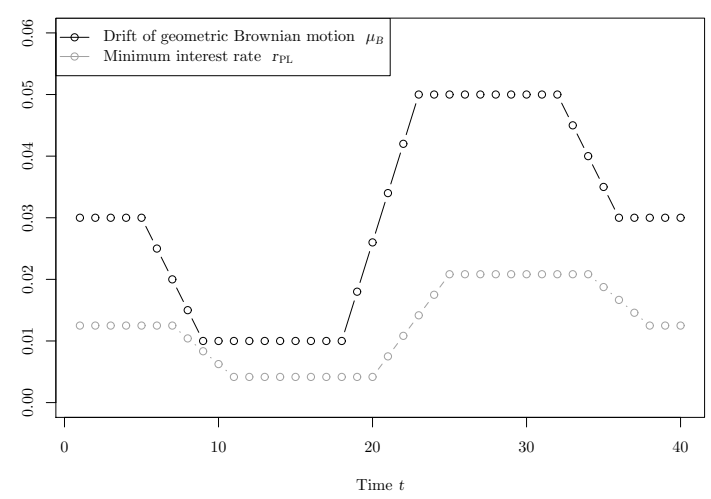

(b) $\mu_{B}$ and $r_{\mathrm{PL}}$ for Scenario 2 .

Figure 8: Illustration of the drift $\mu_{B}$ of the geometric Brownian motion and the minimum interest rate $r_{\mathrm{PL}}$ for scenarios 1 and 2 .

\begin{tabular}{|c|c|c|c|c|c|c|c|c|c|c|}
\hline & 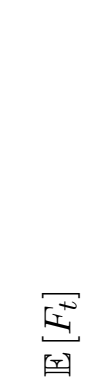 & 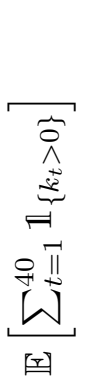 & 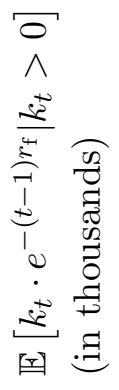 & 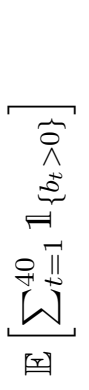 & 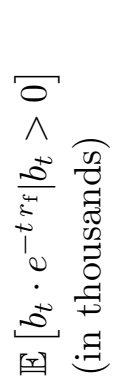 & 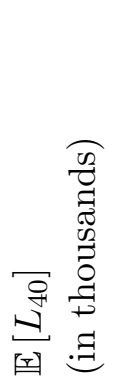 & 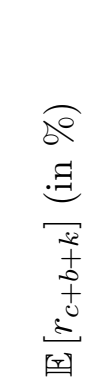 & 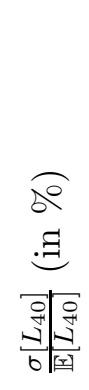 & 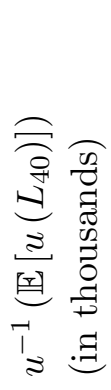 & 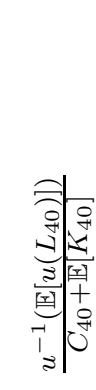 \\
\hline Reference case & 1.04 & 7.9 & 3.04 & 11.6 & 7.91 & 501.7 & 2.74 & 15.2 & 423.2 & 1.076 \\
\hline Scenario 1 & 1.04 & 8.1 & 3.71 & 11.8 & 6.94 & 468.1 & 2.17 & 14.2 & 403.1 & 1.041 \\
\hline Scenario 2 & 1.04 & 8.2 & 2.67 & 11.8 & 9.26 & 549.5 & 3.33 & 16.1 & 450.8 & 1.111 \\
\hline
\end{tabular}

Table 5: Simulation results for the reference case (C) and scenarios 1 and 2 (cf. Table 1).

For the second scenario, the development of $F_{t}$ is analogous. After an increase during the first periods, the lower drift causes the mean funding ratio to drop to approximately $102.5 \%$. In the subsequent periods with higher market returns, $F_{t}$ rises to nearly $106 \%$. With $\mu_{\mathrm{B}}$ returning to $3 \%$, the funding ratio decreases to $104 \%$. As in the first scenario, $F_{t}$ reacts quickly to changes in $\mu_{\mathrm{B}}$ and stays nearly constant once the drift stabilizes. The expected value of $F_{t}$ over all 40 periods is again equal to $104 \%$. It can thus be concluded that two periods of high and low capital market returns of similar severity and length do not influence the expected funding ratio, regardless of how they are ordered.

Remediation Measures $\boldsymbol{k}_{t}$ Figure 10 depicts the present values of the remediation measures payed. In the first case, $k_{t}$ initially stays very low, hardly exceeding CHF 200. This is because the high returns lead to overfunding. With the subsequent drop of $\mu_{\mathrm{B}}$, the additional payments escalate quickly, reaching almost CHF 2000. Towards the end of the time frame, the curve first decreases and then rejoins the course of the reference case, settling at approximately CHF 1500 . The remediation measures for the second scenario grow regularly until the end of period 20, exceeding CHF 500. The successive higher market returns then cause them to halve. While $\mu_{\mathrm{B}}$ equals $5 \%$, the remediation measures again grow only slowly. With the drift returning to $3 \%, k_{t}$ increases strongly. In time $T$, its mean is above CHF 2000 . Comparing the 


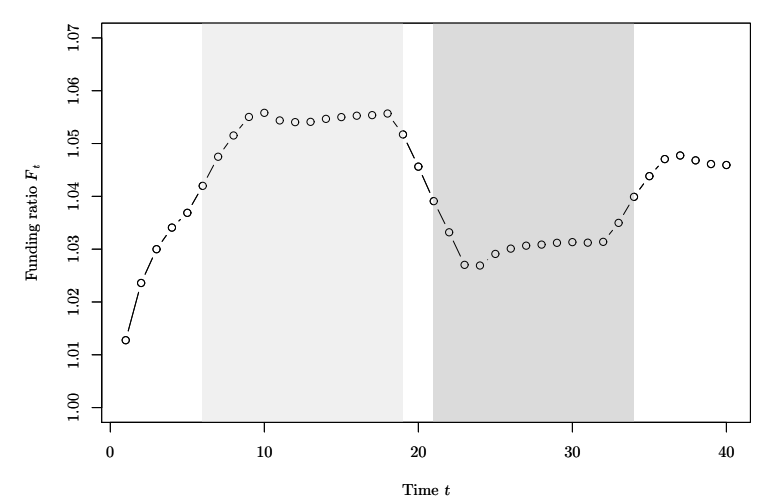

(a) Mean of the funding ratio $F_{t}$ in scenario 1 .

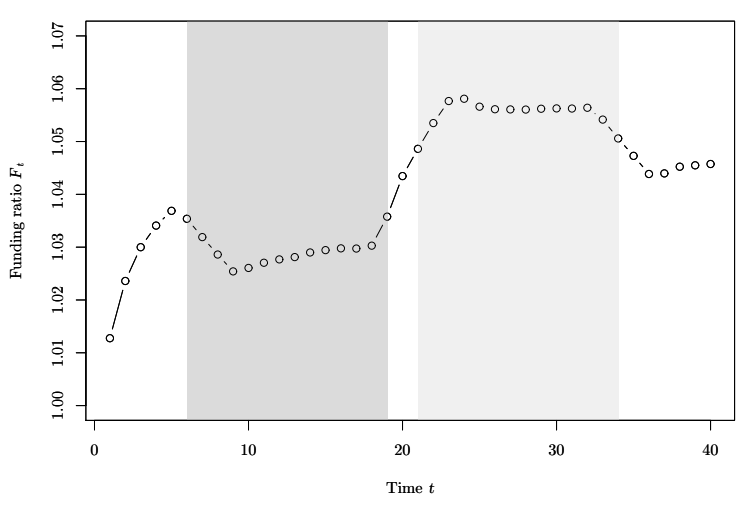

(b) Mean of the funding ratio $F_{t}$ in scenario 2 .

Figure 9: Illustration of the means of the funding ratio $F_{t}$ in scenarios 1 and 2 .

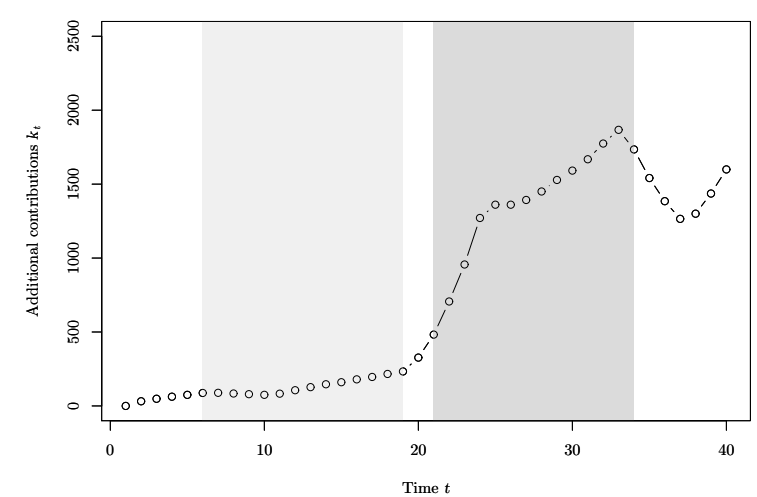

(a) Present value of the remediation measures $k_{t}$ in scenario 1.

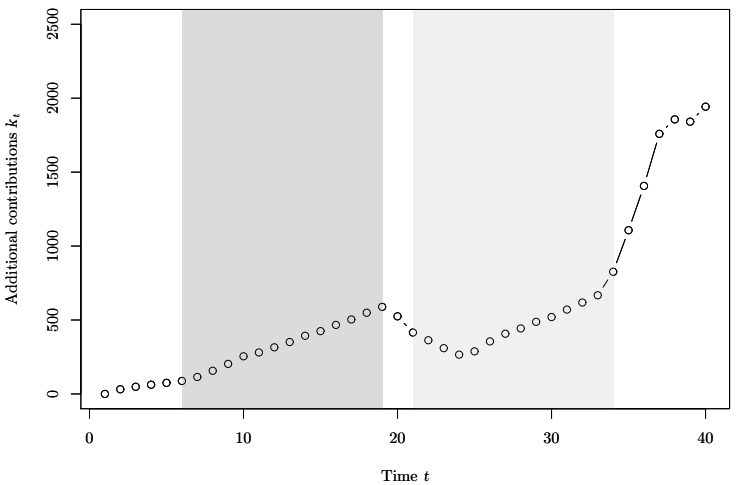

(b) Present value of the remediation measures $k_{t}$ in scenario 2 .

Figure 10: Illustration of the present values of the remediation measures $k_{t}$ in scenarios 1 and 2 .

two cases through Table 5, the expected number of additional payments is almost the same, exceeding the reference case. The expected amount that is paid is higher for the first scenario, reaching more than CHF 3710. The second scenario is approximately $30 \%$ lower than that with the reference case located almost in the middle between the two cases. The reason for the differences in $\mathbb{E}\left[k_{t} \cdot e^{-(t-1) r_{\mathrm{f}}} \mid k_{t}>0\right]$ can be found in the development of the contributor accounts over time. When capital market returns are low at early time points, the amounts needed to compensate are still relatively low. At later times, the required amounts are much larger as assets $A_{t}$ and contributions $C_{t}$ are much higher.

Distributed Surpluses $\boldsymbol{b}_{\boldsymbol{t}}$ For the first scenario, the present value of the bonus payments increases very little at the beginning, reaching approximately CHF 2000. The low capital market returns then cause a slight decline, which is followed by an increase similar to that at the beginning. The recovery of $\mu_{\mathrm{B}}$ to $3 \%$ then leads to a strong increase to about CHF 6000 . For the second case, the payments during the first 20 periods only reach approximately CHF 1000 . The high returns in later times lead to very high mean surpluses being distributed reaching a maximum of about CHF 7000 . The return of $\mu_{\mathrm{B}}$ to $3 \%$ only leads to a small decrease before the curve proceeds to grow as in the reference case.

While the expected number of bonus payments in Table 5 amounts to nearly 12 for both scenarios, the expected distributed surpluses are a lot higher in the second scenario (CHF 9 260). 


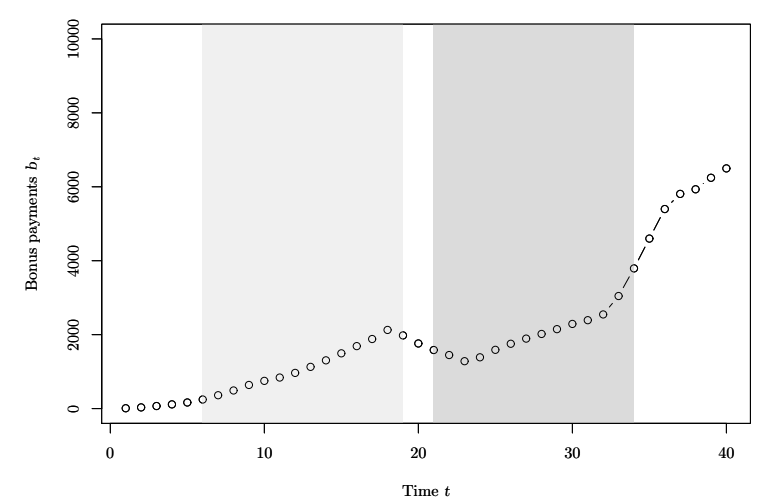

(a) Present value of the distributed surpluses $b_{t}$ in scenario 1.

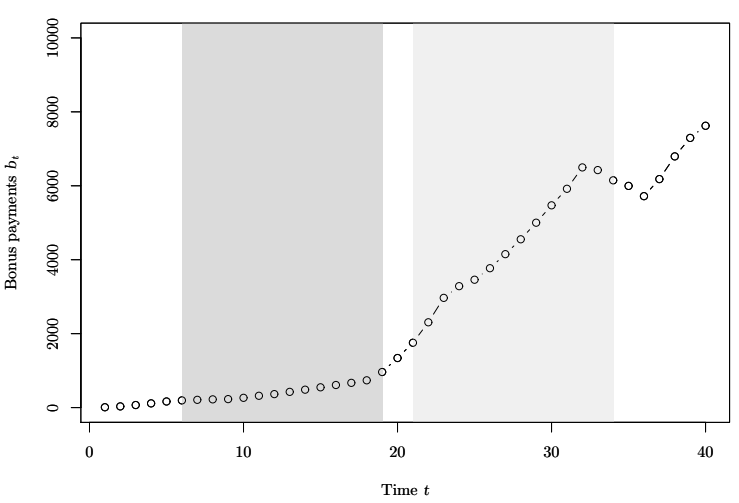

(b) Present value of the distributed surpluses $b_{t}$ in scenario 2.

Figure 11: Illustration of the present values of the distributed surpluses $b_{t}$ in scenarios 1 and 2 .

The reference case has fewer time points where bonuses are being paid and an expected value for $b_{t}$ that lies between the two cases.

Liabilities and Certainty Equivalent For the second scenario the expected value of the liabilities $\mathbb{E}\left[L_{40}\right]$ is higher than for the first, amounting to a difference of more than CHF 80000 . For $\mathbb{E}\left[r_{c+b+k}\right]$, there is an increase. The lower remediation measures lead to a growth of the effective return. Both impacts together cause a strong increase of $\mathbb{E}\left[r_{c+b+k}\right]$. In the second scenario, the effective return is $3.33 \%$. The first case only reaches $2.17 \%$. For the certainty equivalent, the results are similar to the expected liabilities. While the second scenario reaches about CHF 450000 , the first one only exceeds CHF 400000 . This also holds for $u^{-1}\left(\mathbb{E}\left[u\left(L_{40}\right)\right]\right) /\left(\mathbb{E}\left[C_{40}\right]+\mathbb{E}\left[K_{40}\right]\right)$. Here, the reference case has a value of 1.076. The first scenario is close to this, reaching 1.041. The second one reaches 1.111. Analyzing the relative volatility $\sigma\left[L_{40}\right] / \mathbb{E}\left[L_{40}\right]$, the first scenario has the lowest fluctuation, with a value of $14.2 \%$. While obtaining the highest effective returns, the second scenario is also coupled to a high volatility of $16.1 \%$.

\section{Discussion and Conclusion}

Remediation Measures Considering the cases without (A) and with additional contributions (B), we observe an improvement of funding levels connected with their charging. While the higher quantiles are in good funding, the $1 \%$ quantile remains below $100 \%$ if no remediation measures are charged. In case (B), we see an improvement of this subgroup. Utilizing remediation measures thus leads to a stabilization of the fund.

Surplus Distribution With only remediation measures being charged, the funding ratio rises above $100 \%$ in the considered reference setting. Therefore, excessive funds can be distributed, leading to an increase in the insured's absolute certainty equivalent. Additionally, bonuses exceed remediation measures. However, with increasing bonuses remediation costs increase as well, causing higher volatility in the annual payments and thus lower utility relative to the total costs for the policyholder. 
Calibration Remediation measures lead to an improved stability of pension funds. For this to be fully effective, an adequate assignment of all model parameters is essential. Small changes in variables can already lead to a strong impact on the outcomes. For example, a decrease in $F_{\min }$ of only $2 \%$ in case (C) leads to an increase of $k_{t}$ of more than $40 \%$.

Interim Valuation When members leave a fund, additional contributions remain with the fund while bonuses leave with the insured. Our results show that the insured's account is still fairly low after 10 and 20 years. It can therefore be concluded that a change of pension funds can be made without a large impact on the savings. This circumstance, however, changes dramatically in later years.

Capital Market Scenarios Letting the capital market returns follow a predefined path, we imitate periods of both very low and very high returns. The results show that, especially for later years, additional contributions can rise substantially if a funding gap occurs. The same is true for the distributed surpluses. The amounts that are charged or distributed can make up a great percentage of the overall cash flows. Capital market scenarios therefore need to be taken into account with close attention.

Risk Bearing With the worldwide trend from defined benefit (DB) plans towards defined contribution (DC) plans, it is interesting to put our findings into this overall context. In fact, while in DC plans the policyholders can often choose the investment strategy, they bear a large part of the capital market risks since mostly only minimum benefits are guaranteed upfront. Looking at changing interest rate assumptions, Godwin et al. (1996) find that funds are likely to change their interest rate assumptions to increase their latitude concerning contractual relationships. Poterba et al. (2007) find that on average the retirement wealth from DC plans exceeds the one from DB plans. However, DC schemes are more likely to generate very low outcomes. In a similar spirit, Vigna and Haberman (2001) analyze the financial risk in a DC pension plan to derive an optimal investment strategy. They conclude that there is a large variability in the level of pension achieved at retirement. Our results are in line with these findings. As the distribution of bonuses increases the volatility of the payoff, the relative certainty equivalent of risk averse individuals decreases.

Policy Recommendations This work analyzes the value of the accounts of the insured at retirement. We observe that the utilized funding mechanisms and their specific calibration can have an important impact on the stability of the fund and the utility of its contributors. In our model, the charging of remediation measures and the distribution of surpluses takes place automatically. In practice, decisions concerning these actions would typically be made by the funds board. From this we conclude that the role of the board and the governance is crucial for the management of a fund. Although our model is fitted to the Swiss pension fund system, an interpretation of our findings in the light of the rules in place in other countries and an extension of the results to other types of DC pension plans should be straightforward. Also, in practice, the administration costs, the mortality of the members and the decumulation phase where pensions are paid out should be accounted for to get more realistic results. Nevertheless, we observe that while considering solvency constraints, distributing bonuses may increase the risks borne by policyholders and the common belief of policyholders profiting from surplus distribution is a fallacy. Given the current trends of the low interest rate environment and volatility in many markets, such mechanisms should be used with caution. 


\section{References}

Albrecher, H., P. Embrechts, D. Filipović, G. W. Harrison, P. Koch, S. Loisel, P. Vanini, and J. Wagner, 2016, Old-age provision: past, present, future, European Actuarial Journal.

Alestalo, N. and V. Puttonen, 2006, Asset allocation in Finnish pension funds, Journal of Pension Economics and Finance, 5(01):27-44.

Avanzi, B., L. F. B. Henriksen, and B. Wong, 2016, On the Distribution of the Excedents of Funds with Assets and Liabilities in Presence of Solvency and Recovery Requirements, Working Paper, from http://ssrn.com/abstract=2824887.

Avanzi, B. and S. Purcal, 2014, Annuitisation and cross-subsidies in a two-tiered retirement saving system, Annals of Actuarial Science, 8(2):234-252.

Bacinello, A. R., 1988, A Stochastic Simulation Procedure for Pension Schemes, Insurance: Mathematics and Economics, 7(3):153-161.

Berdin, E. and H. Gründl, 2015, The Effects of a Low Interest Rate Environment on Life Insurers, The Geneva Papers on Risk and Insurance - Issues and Practice, 40(3):385-415.

Bischofberger, A. and R. Walser, 2011, Altersvorsorge auf dem Prüfstand - Ein Debakel als Chance, Avenir Suisse Policy Brief, 1.

Björk, T., 2004, Arbitrage Theory in Continuous Time. Oxford University Press.

Black, F., 1976, The Investment Policy Spectrum: Individuals, Endowment Funds and Pension Funds, Financial Analysists Journal, 32(1):23-31.

Braun, A., P. Rymaszewski, and H. Schmeiser, 2011, A Traffic Light Approach to Solvency Measurement of Swiss Occupational Pension Funds, The Geneva Papers on Risk and Insurance Issues and Practice, 36(2):254-282.

Brent, R. P., 1974, Algorithms for Minimization Without Derivatives, IEEE Transactions on Automatic Control, 19(5):632-633.

Broeders, D., A. Chen, and B. Koos, 2011, A Utility-Based Comparison of Pension Funds and Life Insurance Companies under Regulatory Constraints, Insurance: Mathematics and Economics, 49(1):1-10.

Broeders, D., D. Chen, P. Minderhoud, and W. Schudel, 2016, Pension Funds Herding, Working Paper.

BVG 'Bundesgesetz über die berufliche Alters-, Hinterlassenen- und Invalidenvorsorge', from https://www .admin.ch/opc/de/classified-compilation/19820152/index.html, (1 January), 2015.

BVV2 'Verordnung über die berufliche Alters-, Hinterlassenen- und Invalidenvorsorge', from ht tps://www.admin.ch/opc/de/classified-compilation/19840067/index.html, (1 April), 2016.

Cairns, A. J., D. Blake, and K. Dowd, 2006, Stochastic Lifestyling: Optimal Dynamic Asset Allocation for Defined Contribution Pension Plans, Journal of Economic Dynamics and Control, 30(5):843-877. 
Chen, A. and S. Clever, 2015, Optimal Supervisory Rules for Pension Funds under Diverse Pension Security Mechanisms, European Actuarial Journal, 5(1):29-53.

Cosandey, J., 2014, Generationenungerechtigkeit überwinden.

Credit Suisse Economic Research, 2014, Schweizer Pensionskassen 2014: Perspektiven in der Demografie und im Anlagemanagement, Technical Report.

Dufresne, D., 1989, Stability of Pension Systems When Rates of Return Are Random, Insurance: Mathematics and Economics, 8(1):71-76.

Eling, M., 2012, Der Generationenvertrag in Gefahr: Eine Analyse der Transfers zwischen Jung und Alt in der Schweiz.

Eling, M. and S. Holder, 2013, The value of interest rate guarantees in participating life insurance contracts: Status quo and alternative product design, Insurance: Mathematics and Economics, 53(3):491-503.

Eling, M. and D. Kiesenbauer, 2013, What Policy Features Determine Life Insurance Lapse? An Analysis of the German Market, Journal of Risk and Insurance, 81(2):241-269.

FZG 'Bundesgesetz über die Freizügigkeit in der beruflichen Alters-, Hinterlassenen- und Invalidenvorsorge', from https://www.admin.ch/opc/de/classified-compilation/1993037 5/index.html, (1 December), 2016.

Gerber, H. U. and E. S. W. Shiu, 2003, Geometric Brownian Motion Models for Assets and Liabilities: From Pension Funding to Optimal Dividends, North American Actuarial Journal, $7(3): 37-51$.

Ghilarducci, T., 2010, The future of retirement in aging societies, International Review of Applied Economics, 24(3):319-331.

Godwin, J., S. Goldberg, and J. Duchac, 1996, An Empirical Analysis of Factors Associated with Changes in Pension-Plan Interest-Rate Assumptions, Journal of Accounting, Auditing E3 Finance, 11(2):305-322.

Jacquemart, C., 2014, Weniger Reserven, mehr Zins, NZZ am Sonntag, No 34:35.

Lisse, S., 2014, Der höchstmögliche Deckungsgrad ist nicht unbedingt der beste, finews.ch, 25th Aug.

Maas, P., J.-L. Cachelin, and P. Bühler, 2015, 2050: Megatrends : Alltagswelten, Zukunftsmärkte. Institut für Versicherungswirtschaft, St. Gallen.

Mirza, C. and J. Wagner, 2016, Policy Characteristics and Stakeholder Returns in Participating Life Insurance: Which Contracts Can Lead to a Win-Win?, Working Paper.

O'Brien, T., 1986, A Stochastic-Dynamic Approach to Pension Funding, Insurance: Mathematics and Economics, 5(2):141-146.

OECD, 2015a, Pension Market in Focus, from http://www.oecd.org/finance/private-pens ions/pensionmarketsinfocus.htm. 
OECD, 2015b, Pensions at a Glance 2015: OECD and G20 Indicators, from http://www. oecd .org/publications/oecd-pensions-at-a-glance-19991363.htm.

Poterba, J., J. Rauh, S. Venti, and D. Wise, 2007, Defined Contribution Plans, Defined Benefit Plans, and the Accumulation of Retirement Wealth, Journal of Public Economics, 91(10):2062-2086.

Schmeiser, H. and J. Wagner, 2014, A Proposal on How the Regulator Should Set Minimum Interest Rate Guarantees in Participating Life Insurance Contracts, The Journal of Risk and Insurance, 82(3):659-686.

Schweizerische Kammer der Pensionskassen-Experten, 2012, PKST/TSIP - Solvenztest für Schweizer Pensionskassen.

Sharpe, W. F., 1976, Corporate Pension Funding Policy, Journal of Financial Economics, 3(3):183-193.

Swisscanto, 2015, Pensionskassen-Monitor, from http://www.swisscanto.ch/.

UBS, 2014, Altersvorsorge: Lasten in die Zukunft verschoben, Technical Report.

Vigna, E. and S. Haberman, 2001, Optimal Investment Strategy for Defined Contribution Pension Schemes, Insurance: Mathematics and Economics, 28(2):233-262. 